\title{
Using Harvest Slot Limits to Promote Stock Recovery and Broaden Age Structure in Marine Recreational Fisheries: a case study
}

Jacob M. Kasper

University of Connecticut - Storrs, jacob.kasper@uconn.edu

Jeffrey Brust

New Jersey Department of Environmental Protection, Jeffrey.Brust@dep.nj.gov

Amanda Caskenette

Fisheries and Oceans Canada, Amanda.Caskenette@dfo-mpo.gc.ca

Jason McNamee

Rhode Island Department of Environmental Management, jason.mcnamee@dem.ri.gov

Jason C. Vokoun

University of Connecticut - Storrs

See next page for additional authors

Follow this and additional works at: https://opencommons.uconn.edu/eeb_articles

Part of the Marine Biology Commons, and the Terrestrial and Aquatic Ecology Commons

\section{Recommended Citation}

Kasper, Jacob M.; Brust, Jeffrey; Caskenette, Amanda; McNamee, Jason; Vokoun, Jason C.; and Schultz, Eric T., "Using Harvest Slot Limits to Promote Stock Recovery and Broaden Age Structure in Marine Recreational Fisheries: a case study" (2020). EEB Articles. 48.

https://opencommons.uconn.edu/eeb_articles/48 


\section{Authors}

Jacob M. Kasper, Jeffrey Brust, Amanda Caskenette, Jason McNamee, Jason C. Vokoun, and Eric T. Schultz 
Using Harvest Slot Limits to Promote Stock Recovery and Broaden Age Structure in Marine

$\underline{\text { Recreational Fisheries: a case study }}$

Jacob M. Kasper

Department of Ecology and Evolutionary Biology, University of Connecticut, 75 N. Eagleville Road, Unit 3043, Storrs, CT 06269-3043, USA

Jeffrey Brust ${ }^{1}$

New Jersey Department of Environmental Protection, Bureau of Marine Fisheries, PO Box 418 (USPS), 360 N New York Rd (street), Port Republic, NJ 08241

\section{Amanda Caskenette ${ }^{1}$}

Fisheries and Oceans Canada1219 Queen Street East, Sault Ste. Marie, ON., P6A 2E5

\section{Jason McNamee ${ }^{1}$}

Rhode Island Department of Environmental Management, 3 Ft. Wetherill Rd., Jamestown, RI 02835

\section{Jason C. Vokoun}

Department of Natural Resources and the Environment, Wildlife and Fisheries Conservation Center, University of Connecticut,1376 Storrs Road, Unit 4087, Storrs, CT 06269-4087

\section{Eric T. Schultz}

Department of Ecology and Evolutionary Biology, University of Connecticut, 75 N. Eagleville Road, Unit 3043, Storrs, CT 06269-3043, USA

${ }^{1}$ These authors contributed equally 


\section{$<\mathrm{A}>$ Abstract}

2 Fish populations with broad age distributions are expected to have higher reproductive capacity

3 than age-truncated populations because of the disproportionate contributions of older fish.

4 Harvest slot limits, an expected means of ameliorating age truncation, are modeled for Tautog

5 Tautoga onitis in an overfished population subunit that is experiencing overfishing. Tautog,

6 currently managed by a $40 \mathrm{~cm}$ minimum size limit (MSL), is a candidate species for slots

7 because it is relatively long-lived, slow-growing, with low discard mortality. We evaluated

8 changes in biomass and abundance-at-age relative to management with the current MSL

9 regulations using a forward population simulation model for four slots: 35-45 (small-wide), 38-

1042 (small-narrow), 40-50 (large-wide), and 43-47 (large-narrow) cm, inclusive. Angler

11 behavioral responses were evaluated at $0 \%, 10 \%$, and $20 \%$ noncompliance with the upper slot

12 limit. The biomass and number of fish removed are reduced with harvest slot limit management,

13 relative to the MSL, but because the harvest is redirected to smaller fish the reduction in numbers

14 removed is not as large as the reduction in biomass removed. Slot limits broadened the age

15 structure within 10 years by reducing fishing mortality on extant fish. Median spawning stock

16 biomass (SSB) recovered more quickly in three of the slots than with MSL regulation (three to

17 six years to reach $\mathrm{SSB}_{\text {Threshold }}$ as compared to nine years with MSL management). We concluded

18 that harvest slot limits can broaden age structure and restore biomass in overfished fisheries, but

19 should be evaluated when managing coastal fisheries as a reduction in biomass removed is

20 required.

$22<\mathrm{A}>$ Introduction

$23 \quad$ Fishing truncates fish population size structure and age structure due to increased

24 mortality rates on larger and older individuals. This is a global pattern; 61 of 63 fished

25 populations displayed a decreased proportion of individuals in the oldest age classes (Barnett et

26 al. 2017). While fisheries theory predicts some positive effects of size and age truncation, for

27 example, reduced intraspecific competition and increased individual growth rates (Silliman and

28 Gutsell 1958; Arlinghaus et al. 2010; Kindsvater and Palkovacs 2017), truncation can have long-

29 lasting negative impacts. Offspring quantity may be reduced in populations with truncated

30 size/age structure because, on a per-weight basis, larger females produce more offspring than

31 smaller females (e.g. LaPlante and Schultz 2007). Offspring quality may also be reduced in

32 populations with truncated size/age structure, as older fish in some species produce faster 
33 growing and more provisioned offspring than younger fish (maternal effects, Berkeley et al.

34 2004; Sogard et al. 2008; Carr and Kaufman 2009; but see Marshall et al. 2010). Populations

35 with truncated size/age structure have exhibited reduced resilience (i.e. the buffering capacity in

36 response to environmental change) and increased recruitment variability (Anderson et al. 2008;

37 Cooper et al. 2013). Thus, even when biomasses are equivalent, stocks composed of younger fish

38 may be less resilient (to fishing and environmental fluctuation) and have lower recruitment than

39 stocks composed of older fish (Wright and Trippel 2009; Rouyer et al. 2011; Botsford et al.

40 2014; Hixon et al. 2014; Barneche et al. 2018). Conversely, if a truncated age structure is

41 broadened, then recruitment variability may decrease and resilience may increase. Methods to

42 reverse age truncation have been proposed but there remains a dearth of case studies that

43 evaluate species-specific strategies to broaden age structure in the context of actionable

44 management measures.

45 Truncated age structures can be broadened by reducing fishing mortality on larger/older

46 individuals through modifying fishery selectivity (age-specific vulnerability). Various means of

47 modifying selectivity include: marine reserves (Palumbi 2004; Berkeley 2006), gear

48 modifications (Fauconnet and Rochet 2016; Garner et al. 2017), and harvest length regulations

49 (Berkeley 2006; Cooper et al. 2013; Hixon et al. 2014; Gwinn et al. 2015; Le Bris et al. 2018).

50 Here we focus on harvest length regulations because of their widespread and effective use in

51 recreational fisheries management (van Poorten et al. 2013). Typically, harvest length

52 regulations consist of minimum size limits (MSL, producing an asymptotic selectivity curve)

53 which can reduce the abundance of the largest/oldest fish. When additional harvest reduction is

54 required the minimum size is often increased, focusing the harvest on an ever-decreasing pool of 55 larger, older, fish. In contrast, harvest slot limits — where only fish within a prescribed size range 
56 may be harvested and the others must be released - disproportionately select fish within the slot

57 (producing a dome-shaped selectivity curve). Harvest slot limits should protect older individuals

58 and could also be effective at achieving management objectives.

Harvest slot limits have been implemented in limited marine commercial (Le Bris et al. 2018) and marine recreational fisheries (Armstrong et al. 1996; Pierce 2010; Powers et al. 2012; ASMFC 2013; Muller et al. 2015; Schmidtke et al. 2017; FL FWCC 2019; MD DNR 2019; NYS DEC 2019; WA DFW 2019; GMFMC 2020). In some marine recreational fisheries, harvest slots

63 have been implemented and, apparently, not evaluated. While in other marine recreational

64 fisheries, harvest slot limits have been evaluated, but not implemented (Leaf et al. 2008; Dippold et al. 2016; Morson et al. 2017). These case studies, however, did not explicitly explore the effects of broadening age structure on the population. A case study of Red Drum Sciaenops ocellatus, which was managed by slot limits, estimated the daily bag limit required to meet the management target but did not project the changes in the population dynamics as a result of such regulatory changes (Vaughan and Carmichael 2002). Other contributions modeled the impact of harvest slot limits on the age structure of Black Rockfish Sebastes melanops and simulated

71 species (Berkeley 2006; Gwinn et al. 2015, respectively). In these examples, harvest slot limits

72 are predicted to protect older age classes (Berkeley 2006) and increase the catch of trophy fish

73 (Gwinn et al. 2015). These studies, however, did not evaluate the use of harvest slot limits as a

74 tool to simultaneously rebuild spawning stock biomass (SSB) and broaden age structure in

75 overfished-age-truncated stocks currently in need of directed management.

Here we provide a case study simulating the implementation of harvest slot limits on a

77 species regionally popular among marine recreational anglers, Tautog Tautoga onitis. Tautog is

78 cooperatively managed through the Atlantic States Marine Fisheries Commission (ASMFC); 
79 individual states ( $\mathrm{NC}$ to $\mathrm{MA}$ ) have the authority to implement specific management measures, so

80 long as they meet the overall ASMFC management objective. The most recent stock assessment

81 concluded that Tautog in the Long Island Sound component of the coastwide population is

82 overfished and experiencing overfishing in the terminal year (ASMFC 2016). The recreational

83 sector accounts for $90 \%$ of the harvest (ASMFC 2016) and Tautog has a low discard mortality

84 rate of $2.5 \%$ (Simpson 1999). Tautog egg production on a per-gram basis increases

85 hyperallometrically with length; in one season, $50 \mathrm{~cm}$ females produced 24-86 times as many

86 eggs as $25 \mathrm{~cm}$ females (LaPlante and Schultz 2007) whereas the difference would be only eight

87 times were the scaling isometric. Tautog is relatively long-lived (maximum recorded age is 34

88 years) and slow-growing (Cooper 1967) compared to other recreationally exploited species in the

89 Northwest Atlantic, making them particularly vulnerable to age size/truncation. In fact, the

90 median size of female Tautog caught in the Connecticut Long Island Sound Trawl Survey

91 declined $20 \mathrm{~mm}$ between 1984 and 2005 (LaPlante and Schultz 2007). Despite increasingly strict

92 regulations (increased minimum size, decreased bag limits, and shortened season), Tautog SSB

93 in the region has not recovered (ASMFC 2016). Restoring the abundance of larger/older

94 individuals may promote stock recovery and enhance angler experience (Gwinn et al. 2015).

95 The objectives of this study were to 1) evaluate the age structure of Tautog in Long

96 Island Sound, 2) develop and parameterize a population dynamics model to evaluate the effect of

97 varying length limits, and 3) evaluate the sensitivity of results to varying levels of angler

98 noncompliance. Four slot types were analyzed: a two by two combination of median size (small

99 and large) and slot breadth (narrow and wide). We tested the hypothesis that harvest slot limits

100 will broaden age structure and restore SSB in an overfished region. Spawning stock biomass was

101 used as the metric of stock size rather than total egg production; it is more widely employed in 
102 stock assessments because it can be more readily quantified. To estimate these changes

103 appropriately, we reparametrized the Long Island Sound region stock assessment. Using the new

104 assessment, harvest slot limits were evaluated using scenario-specific removal quantities and

105 selectivity curves in forward population simulations. Finally, sensitivity analyses were performed

106 to estimate the impact of angler noncompliance with the upper slot limit.

$107<$ A $>$ Methods

108 Data.-Data used in this study are similar to data used for other species managed with statistical

109 catch-at-age stock assessments. Tautog in Long Island Sound (CT and NY north shore of Long

110 Island) are assessed and managed as a subunit of the coastwide stock. CT, NY, the US federal

111 government, and the American Littoral Society maintain long-term databases describing the

112 biological and fishery characteristics in the region (Figure 1, Table 1, ASMFC 2016). Fishery-

113 independent surveys, fishery-dependent surveys, and biological studies were used to

114 parameterize the stock assessment model (Figure 1). The stock assessment model quantified

115 current SSB, biological reference points, recruitment, age structure, and fishing mortality. These

116 derived quantities were used to perform forward population simulations under different

117 management scenarios. Removals (biomass and numbers) and selectivity curves were predicted

118 for each potential management scenario evaluated from angler catch-at-length data. Forward

119 population simulations were used to forecast changes in SSB and abundance-at-age under

120 conditions of constant removals and selectivity curves within each management scenario.

121 Fishery-independent surveys provided abundance indices, length-at-age observations, and

122 length-weight relationships (Figure 1, Table 1). An independent index of Tautog abundance

123 (numbers per tow) was developed using the CT Long Island Sound Trawl Survey, a stratified-

124 random survey (CT Department of Energy and Environmental Protection 2016), using a negative 
125 binomial generalized linear model (GLM) with a formula including abundance $\sim$ year + month +

126 stratum, an approach that is consistent with that used for the stock assessment (ASMFC 2016).

127 Additionally, and also consistent with the stock assessment, age-1 abundance indices (numbers

128 per tow) were developed from the Peconic Bay Small Mesh Trawl Survey (McCandless and

129 Grahn 2014) and the Western Long Island Sound Juvenile Abundance (seine) Survey using

130 GLMs: the Peconic survey formula used, abundance $~$ year; the Western Long Island sound

131 formula used, abundance $\sim$ year + temperature (ASMFC 2016). Fish from these three surveys

132 were aged (opercular bones), measured for total length in millimeters, and in the case of the CT

133 survey, weighed and sexed (ASMFC 2016).

134 Fishery-dependent programs characterized the fishery (Figure 1, Table 1). National

135 Marine Fisheries Service's Marine Recreational Fisheries Statistics Survey and Marine

136 Recreational Information Program (personal communication from the National Marine Fisheries

137 Service, Fisheries Statistics Division 2016) provided the fishing effort index, estimated the

138 numbers of fish caught/harvest, and contributed to the harvest/discards-at-length observations.

139 The NY party (head) boat survey, the CT Marine Volunteer Angler Survey Program, and the

140 American Littoral Society tagging program contributed length-at-age (NY survey) and additional

141 harvest- and discard-at-length observations (see Table 1 for specifics, ASMFC 2016). Detailed

142 descriptions of the data preparation are provided (Appendix 1).

143 Stock characteristics and assessment.-The CT survey was used to evaluate changes in female

144 age structure in Long Island Sound (Figure 1). A one-way analysis of variance (ANOVA) was

145 used to test for changes over time in female catch-at-age. We aggregated years into four

146 selectivity blocks (period of relatively consistent regulations) for this test; the same aggregation

147 of years into selectivity blocks was used in both the management assessment (ASMFC 2016) and 
148 the assessment detailed below. Differences in mean catch-at-age were identified with the post-

149 hoc Tukey's honest significant difference test.

150 The stock assessment developed for this analysis covers the same years (1984-2015) and 151 applies the same datasets as the Tautog stock assessment (ASMFC 2016) that is currently used

152 for management. Table 2 provides details of the symbols and parameter estimates, and Appendix

1532 indicates how this model differs from the ASMFC model. Both assessments were performed

154 using the NOAA Fishery Toolbox Age Structured Assessment Program version 3.0.17 (ASAP,

155 NOAA Fisheries Toolbox 2014). ASAP is a statistical catch-at-age model that uses observed

156 catches and indices of abundance to estimate population size and age structure (Legault and

157 Restrepo 1999). Following Legault and Restrepo (1999), SSB at time ( $t$ ) was calculated as the

158 summation across ages $(a)$ of the product of the abundance-at-age $\left(N_{a}\right)$, the proportion mature-at159 age ( $P_{M A}$, Chenoweth 1963), the weight-at-age $\left(W_{a}\right)$, and survivorship, which is the product of

160 the proportion of fish that survive to the spawning period $\left(P_{S S B}\right.$, Cooper 1967) and total

161 mortality-at-age, $Z_{a}$ :

$$
S S B_{t}=\sum_{a} N_{t, a} \cdot P_{M A, a} \cdot W_{t, a} \cdot e^{-P_{S S B} \cdot Z_{t, a}}
$$

162 As spawning does not occur on January 1, total mortality was adjusted for the proportion of the

163 year that occurred prior to spawning. Abundance for age 1 fish was the product of expected

164 recruitment $(R)$ and lognormal recruitment deviations $\left(\log _{-} R d e v\right)$ :

$$
N_{t, 1}=R_{t} \cdot e^{\log _{-} R d e v_{t}} .
$$

165 Recruitment in ASAP was calculated with a Beverton-Holt stock-recruitment relationship. Here 166 the steepness was fixed at 1.0 (expected recruitment was constant) so recruitment was the 
167 quotient of unexploited spawning stock biomass $\left(S S B_{0}\right)$ and unexploited spawners per recruit

$168\left(S P R_{0}\right)$ :

$$
R_{t}=\frac{S S B_{0}}{S P R_{0}}
$$

169 Abundance for ages 2 to the age class younger than the plus group $(A)$ was the product of the

170 abundance of the same cohort in the previous year and survivorship:

$$
N_{t, a}=N_{t-1, a-1} \cdot e^{-Z_{t-1, a-1}}
$$

171 Abundance for the plus group was the summation of the number of fish that survive to the plus

172 group and the survivorship of the previous year's plus group:

$$
N_{t, A}=N_{t-1, A-1} \cdot e^{-Z_{t-1, A-1}}+N_{t-1, A} \cdot e^{-Z_{t-1, A}}
$$

173 Total mortality was the sum of natural mortality (ASMFC 2015) and fishing mortality $\left(F_{a}\right)$ for

174 each age and year:

$$
Z_{t, a}=M+\sum F_{t, a}
$$

175 Fishing mortality was the product of a year effect $(F m u l t)$ and selectivity-at-age $\left(S_{a}\right)$ :

$$
F_{t, a}=\text { Fmult }_{t} \cdot S_{b, a}
$$

176 As in the ASMFC assessment (2016), fishery selectivity was a single logistic curve calculated 177 independently for each of four selectivity blocks $(b)$ :

$$
S_{b, a}=\frac{1}{1+e^{-\left(a-\alpha_{b}\right) / \beta_{b}}}
$$

178 where the midpoint $\left(\alpha_{b}\right)$ and the slope $\left(\beta_{b}\right)$ describe the ascending portion of the function.

179 Fishery selectivity was estimated separately and held constant for each selectivity block $(b=1$

180 for years $1984-1986, b=2$ for years $1987-1994, b=3$ for years $1995-2011, b=4$ for years 
181 2012-2015). Finally, after initial model parameterization, effective sample sizes were reweighted

182 (Francis 2011) before the final stock assessment model run. The reweighted model was then run

183 using Monte Carlo Markov Chain (MCMC) with 1,000 iterations and a thinning factor of 200

184 (200,000 MCMC calculations) to characterize uncertainty in parameter estimates. Fishing

185 mortality reference points were based on spawners per recruit estimated in ASAP; $\mathrm{F}_{\text {Target }}=$

$186 \mathrm{~F}_{40 \% \mathrm{SPR}}$ and $\mathrm{F}_{\text {Threshold }}=\mathrm{F}_{30 \% \mathrm{SPR}}$. Further, $\mathrm{SSB}_{\text {Target }}$ and $\mathrm{SSB}_{\text {Threshold }}$ were the median of terminal

187 SSB values when the stock was managed with $\mathrm{F}_{\text {Target }}$ or $\mathrm{F}_{\text {Threshold }}$ for 55 years in the forward

188 population simulation (detailed below).

189 Population simulations.-_SSB and abundance-at-age for Tautog in the Long Island Sound region

190 were forecasted for each year in a forward population simulation model (Figure 1). Simulations

191 were performed in the Age Structured Projection Model version 4.3 Beta 11 (AgePro, NOAA

192 Fisheries Toolbox 2018) which was integrated with the output from the ASAP model. AgePro is

193 a discrete-time model with an annual time step. Fifty population simulations were performed for

194 each of 1,000 initial population abundance-at-age vectors calculated in the terminal year of the

195 ASAP MCMC model (detailed above); thus each projection consisted of 50,000 simulated

196 population trajectories (Brodziak 2009). These trajectories were used to calculate median and

1975 th/95th percentiles (hereafter referred to as median and confidence limits) of the SSB and

198 abundance-at-age distribution for each of the harvest slot scenarios, relative to MSL

199 management.

200 Simulations for each scenario were run for 55 years — with this timeframe, equilibrium

201 (annual SSB change $<1 \%$ ) was reached for scenarios in which SSB did not crash. Relative

202 changes in abundance-at-age were analyzed after 10 and 55 years of constant removals and

203 selectivity. The 10-year benchmark was selected because preliminary analyses indicated a peak 
204 of relative change around this time. The 55-year benchmark was chosen as it is representative of 205 equilibrium population dynamics. Removals and fishery selectivity were constant over time and 206 unique to each scenario evaluated (detailed below). Life history parameters $\left(P_{M A}, W_{a}, P_{S S B}\right.$, and $207 M$ ) were averaged over selectivity block four of the assessment model, thus we assumed no 208 change in growth parameters in the forecast model. Removal values were the sum of the number 209 harvested and the discard mortality predicted from the catch in the last selectivity block (detailed 210 below). Recruitment was based on random draws from the empirical values estimated in ASAP 211 and was independent of spawning biomass and time. Abundance-at-age in each year was

212 predicted for ages 2 to 15 and for the age plus group with equations (4 and 5), respectively.

213 Finally, SSB was predicted with equation (1).

214 Scenario evaluation.-Thirteen management models - the current management strategy using an

215 MSL of $40 \mathrm{~cm}$ and four harvest slots, each with three different upper slot limit noncompliance

216 rates - were evaluated. The four slots consisted of two different slot breadths $(5 \mathrm{~cm}$ and $11 \mathrm{~cm}$,

217 inclusive of lower and upper length limits) each of which was centered on $40 \mathrm{~cm}$ or $45 \mathrm{~cm}$

218 lengths. The narrow breadth of $5 \mathrm{~cm}$ was selected because a slot narrower than 2 inches seemed

219 unlikely to be implemented. The wide breadth of $11 \mathrm{~cm}$ was employed after preliminary analysis

220 indicated broader slots results in population crash. The $40 \mathrm{~cm}$ slot median (the "small" slots) was

221 chosen to match the current MSL. The $45 \mathrm{~cm}$ median (the "large" slots) was selected as it would

222 enhance the opportunity for anglers to harvest larger fish. We evaluated each of the four slots-

223 35-45 (small-wide), 38-42 (small-narrow), 40-50 (large-wide), and 43-47 (large-narrow) cm,

224 inclusive-assuming $0 \%, 10 \%$, and 20\% noncompliance rates with the upper slot limit size. The

225 noncompliance rates were informed from other fisheries with harvest slot limits: Common Snook 
226 Centropomus undecimalis (5-17\%, Muller et al. 2015) and Northern Pike Esox lucius (13-19\%,

227 Pierce and Tomcko 1998).

228 Harvest slot limit removals.-Removals (the sum of harvest and discard mortality) were fixed

229 rather than time-dependent. Removals and selectivity curves for each scenario were calculated

230 based on the mean harvest- and discards-at-length observations which informed the regional

231 stock assessment for the years 2012-2015, the most recent selectivity block. The MSL scenario

232 was evaluated as if it were a harvest slot limit, but without an upper limit on the slot. All

233 scenarios included a $20.3 \%$ harvest reduction to evaluate performance of these options relative to

234 the required management changes implemented in 2018 (ASMFC 2017). Noncompliance below

235 the minimum size (lower bound of a slot or the MSL) and discard mortality were included in

236 removals (detailed below). Removals in biomass were calculated for each of the 12 slot scenarios

237 and the MSL for use in the forward simulation.

239 and discard mortality. Harvest was the product of the catch-at-length $\left(C_{L}\right)$ and the proportion

240 harvested-at-length $\left(P_{H, L}\right)$. Discard mortality was the product of $C_{L}$, the discard mortality rate

$241\left(F_{D}\right)$, and the proportion discarded $\left(1-P_{H, L}\right)$ :

$$
R_{N}=\sum_{L=11}^{76} C_{L} \cdot P_{H, L}+C_{L} \cdot F_{D} \cdot\left(1-P_{H, L}\right)
$$

242 Similarly, the biomass removed in each scenario was the product of the number removed in each

243 length class and the weight-at-length $\left(W_{L}\right)$ :

$$
R_{B}=\sum_{L=11}^{76} C_{L} \cdot P_{H, L} \cdot W_{L}+C_{L} \cdot F_{D} \cdot W_{L} \cdot\left(1-P_{H, L}\right)
$$


244 Weight-at-length was estimated using the same approach implemented in the stock assessment

245 (Appendix 1). Proportion removals-at-length was estimated in three stanzas: fish smaller than the

246 lower slot limit (the sum of the noncompliant harvest and dead discards), fish within the slot (the

247 sum of the compliant harvest and dead discards), and fish larger than the upper slot limit (the

248 sum of noncompliant harvest and dead discards). For fish smaller than the slot: the catch-at-

249 length data used in the last four years of the stock assessment model included noncompliant

250 harvest of fish below the legal minimum size of $40 \mathrm{~cm}: 11.3 \%$ of the total harvest in numbers

251 were 22 to $39 \mathrm{~cm}$ in length. We assumed that below-slot noncompliance behavior would be the

252 same as noncompliance with the MSL. The proportion of noncompliant harvest $\left(P_{H, L}\right)$ for these

25313 length increments (Table A.3) was applied to the 13 length increments below the minimum

254 size limit of each harvest slot and the MSL. For fish within the slot: Compliant removal-weight-

255 at-length in the harvest slot was reduced by $20.3 \%\left(P_{H, L}=0.797\right)$, as justified above. For fish

256 larger than the slot: proportion harvested $\left(P_{H, L}\right)$, in this case noncompliance, was $0.0,0.1$, or 0.2 .

257 Fishery selectivity.-Selectivity-at-age was parameterized independently for each of the 13

258 scenarios. Removal-at-length $\left(R_{L}\right)$ were calculated by modifying efquation $(9)$ for each length

259 increment using the same data used for the harvest slot limit removal calculation:

$$
R_{L}=C_{L} \cdot P_{H, L}+C_{L} \cdot F_{D} \cdot\left(1-P_{H, L}\right)
$$

260 The $R_{L}$ vector was converted to removal-at-age $\left(R_{a}\right)$ using the multinomial age-length-key

261 approach (Gerritsen et al. 2006) developed with the nnet package in R (Venables and Ripley

262 2002). The multinomial approach, also implemented in our stock assessment (Appendix 1),

263 accounts for highly variable ages within length intervals as well as small sample sizes and

264 missing length intervals. Length-at-age observations (in years 2012-2015) from the CT and NY 
265 trawl survey as well as the NY head (party) boat survey were used to fit the multinomial model.

266 The resulting coefficients (Table A.1) were used to predict the probability of length-at-age with

267 the predict function in R. Scenario-specific $R_{a}$ is, therefore, the probability of length-at-age

268 multiplied by the $R_{L}$ vector. The proportion of removals-at-age $\left(P_{a}\right)$ is $R_{a}$ divided by the total

269 removals $\left(R_{N}\right)$ :

$$
P_{a}=\frac{R_{a}}{R_{N}}
$$

270 Selectivity-at-age $\left(S_{a}\right)$ was estimated by fitting the $P_{a}$ vector to the double logistic equation

$$
S_{a}=\frac{1}{1+e^{-\left(a-\alpha_{1}\right) / \beta_{1}}}+\frac{1}{1+e^{-\left(a-\alpha_{2}\right) / \beta_{2}}}
$$

271 using nonlinear least squares (nls function in R). As with equation (8), $\alpha$ and $\beta$ were the midpoint

272 and the slope of the ascending (subscript 1) and descending (subscript 2) portion of the curve,

273 respectively. Starting values were visually estimated from the $P_{a}$ vector. The $S_{a}$ vector for each

274 scenario was then scaled to a maximum selectivity of one. In a similar manner the $P_{a}$ vector for

275 the MSL scenario was fit to a single logistic equation (8), but omitting the subscript. Selectivity

276 for the MSL scenario was recalculated for two reasons: (1) to maintain consistency in the

277 parameterization of across all scenarios and (2) to account for the change in selectivity due to the

278 previously mentioned 2018 regulatory changes.

$279<$ A $>$ Results

$280<\mathrm{B}>$ Stock characteristics

281 The mean age of female Tautog captured in the Long Island Sound Trawl Survey declined over

282 the last three selectivity blocks and the maximum age of females was the lowest in the most 
283 recent selectivity block, indicating that the population is age-truncated (Figure 2). The

284 reparametrized stock assessment characterized the SSB and fishing effort in the region in a 285 similar manner as the ASMFC assessment, despite differences in the approach. Tautog was 286 overfished in the terminal year: $\operatorname{SSB}_{\text {Terminal }}(1,937 \mathrm{mt})$ was lower than $\operatorname{SSB}_{\text {Target }}(3,397 \mathrm{mt})$ and

$287 \mathrm{SSB}_{\text {Threshold }}(2,549 \mathrm{mt})$. Additionally, overfishing occurred in the terminal year $-\mathrm{F}_{\text {Terminal }}(0.75)$

288 was higher than $\mathrm{F}_{\text {Target }}(0.29)$ and $\mathrm{F}_{\text {Threshold }}$ (0.54). A comparison of biological reference points,

$289 \mathrm{SSB}_{\text {Terminal, }}$, and $\mathrm{F}_{\text {Terminal }}$ between the two approaches is provided (Table A.4).

$290<$ B $>$ Population simulations

291 Harvest slot limit yield.-Changes in slot breadth, slot location, and noncompliant harvest

292 modified removals. Removals decreased relative to MSL regulations in the large slots and small-

293 narrow slot (Table 3). The magnitude of removals was larger with each small slot (small-wide or

294 small-narrow) than with the corresponding large slot (large-wide or large-narrow) of the same

295 breadth. Furthermore, removals were larger with wide slots than with the narrow slot. The small-

296 narrow and large-wide slots generated the smallest change in the number of fish removed

297 compared to MSL. As expected, noncompliance with the upper slot limit increased the estimated

298 removals. The change in removals due to noncompliance was smaller with larger upper slot sizes

299 because abundance decreases with age (Table 3).

300 Fishery selectivity.-Modified length limits changed removals and fishery selectivity. When

301 managed with slot limits, dome-shaped selectivity curves were highest at ages 6 and 7 (Figure 3).

302 In contrast, when managed with an MSL, selectivity increased asymptotically to age 10 and

303 remained high. The selectivity curves for the broad slots are slightly wider than their

304 corresponding narrow slots. Noncompliance with the upper slot limit increased the selectivity of 305 older fish in the narrow slots more than in the wide slots. 
306 Scenario evaluation (SSB). - - Harvest slot limits promoted SSB recovery more quickly and to

307 larger magnitudes than MSL management. Spawning stock biomass recovered with harvest slot

308 management in all but the small-wide slot scenario (Table 4). With the narrow slots, median SSB

309 was larger than with the MSL for the duration of the forward population simulation (Figure 4).

310 The large-wide slot rebuilt to $\mathrm{SSB}_{\text {Target }}$ and $\mathrm{SSB}_{\text {Threshold }}$ more quickly than with MSL

311 management. Interestingly, the median SSB with this slot was larger than the median SSB with

312 MSL for the first 31 years of the projection, after which the MSL maintained larger median SSB.

313 Even when noncompliance is considered, only one scenario (large-wide with $20 \%$

314 noncompliance) took longer to reach the $\mathrm{SSB}_{\text {Target }}$ than with MSL management (Table 4).

315 Scenario evaluation ( $N$-at-age).-Harvest slot limits broadened the age structure of Tautog in the

316 Long Island Sound region by increasing the abundance of older fish (Figure 5). Relative to MSL

317 management, the abundance of older fish increased with slot management. The change in the

318 relative abundance of older fish was more pronounced after 10 years of management than after

31955 years of management, owing to the slower stock recovery when managed by MSL. The

320 median relative abundance for ages five to about ten years (depending on scenario and

321 noncompliance) were depressed with harvest slot management due to the redirected fisheries

322 selectivity. This reduction is more pronounced after 55 years than 10 years of management.

323 Noncompliance decreased the relative abundance of older fish in all models. The small-wide slot

324 is not included as SSB analysis indicated that the stock would not recover with this management

325 approach.

$326<\mathrm{A}>$ Discussion

327 Managing with harvest slot limits broadens age structure and rebuilds SSB more quickly

328 and to larger magnitudes than managing with MSL (Table 3 and Figure 4). Slot limits reduce 
329 removal biomass, relative to management with MSL, but the biomass reduction does not

330 necessitate an equally large reduction in the number of fish removed. Harvest slots are more

331 effective at broadening age structure than MSL. Finally, biological reference points are reached

332 more quickly with slots than MSL management.

Spawning stock biomass rebuilds more quickly with the harvest slots than with MSL

334 management and potentially to larger magnitudes. Rebuilding to $\mathrm{SSB}_{\text {Threshold }}$ and $\mathrm{SSB}_{\text {Target }}$ is

335 faster in three of the compliant scenarios than with MSL management (small-wide being the

336 exception). Harvest slots tolerate noncompliance as only the large-wide with $20 \%$

337 noncompliance scenario took longer to rebuild to $\mathrm{SSB}_{\text {Target }}$ than with MSL management. Based

338 on median SSB values, the small-narrow slot rebuilt to $\mathrm{SSB}_{\text {Threshold }}$ and to $\mathrm{SSB}_{\text {Target }}$ five and

339 fifteen years faster, respectively, while simultaneously broadening age structure. While Tautog is

340 not managed by the Magnuson-Stevens Fishery Conservation and Management Act (MSA) and

341 the Sustainable Fisheries Act (SFA), we considered the stock rebuilding requirements therein.

342 Under federal management, overfished stocks must be rebuilt within 10 years (Sustainable

343 Fisheries Act of the Magnuson-Stevens Fishery Conservation and Management Act 1996). Had

344 this stock been managed by MSA/SFA, a larger stock reduction ( $27 \%$ instead of $20.3 \%$,

345 Appendix 3) would have been required to rebuild to $\mathrm{SSB}_{\text {Target }}$ in 10 years with MSL

346 management. This larger reduction would have been achieved by the large-narrow slot (Figure

347 A1) but was less effective at broadening age structure (Figure A2). Such profound population-

348 level changes make harvest slots a more attractive management measure than traditional

349 approaches for fisheries with low discard mortality rates.

$350 \quad$ Management with harvest slot limits broadens truncated age structure by protecting

351 young-extant-individuals and allowing them to grow older, rather than relying on de novo 
352 recruitment to rebuild the stock. This is evidenced by the finding that within 10 years of slot limit

353 management the abundance of fish older than 10 years increases relative to management with

354 MSL. In the current study, the predicted rapid increase in the relative abundance of older fish

355 indicates that harvest slots are a powerful tool to modify age structure. This recovery is within

356 one or two benchmark stock assessment cycles, which may garner support for these alternative

357 management measures.

We assumed density independence in recruitment. Our model fixed the initial steepness

359 of the stock-recruitment relationship, a notoriously difficult parameter to estimate (Conn et al.

360 2010; Lee et al. 2012). While preliminary analysis estimated the steepness of the stock-

361 recruitment relationship, the parameters were not used because the initial steepness and

362 unexploited SSB were highly correlated (data not shown). Fixing initial steepness renders

363 recruitment independent of SSB which may seem contradictory to the goal of increasing SSB.

364 This is nonetheless a common practice in stock assessments (Mangel et al. 2013), and is resolved

365 by implementing spawning potential ratio based reference points. Incorporating density

366 dependence in recruitment would reduce the estimated rate of recruitment when SSB is below

367 the target or threshold, and could delay the recovery in SSB. Incorporating density-dependent

368 recruitment would not impact the extent to which age structure broadens in the short term (e.g.,

369 would not affect the proportion of fish older than 10 years after only 10 years of management)

370 but could affect predicted age structure over a longer timeframe. Experimental studies suggest

371 that density dependence in recruitment has a relatively modest effect: in freshwater systems that

372 could be expected to impose density dependence in recruitment, harvest slot regulations are

373 effective at broadening age structure (Pierce 2010; Tiainen et al. 2017). 
For general applicability, we chose to assess reproductive capacity with SSB rather than

375

376

377

378

379

380 egg production. This metric aligns our study with traditional stock assessment approaches and provides utility for fisheries managers to apply our methods to other species (which are mostly managed by SSB). For example, the ASMFC measures reproductive capacity with total egg production for only Atlantic Menhaden Brevoortia tyrannus (SEDAR 2020). Additionally, Tautog—like many marine species—exhibit asynchronous oocyte development (White et al. 2003) making annual fecundity estimates challenging, expensive, and error-prone (McBride et al. 2015). As such, despite the availability of annual fecundity estimates for Tautog in this region (LaPlante and Schultz 2007), we chose to evaluate with SSB. Measuring reproductive capacity with SSB rather than egg production may underrepresent the impact of harvest slot limits. On a per-gram basis, larger Tautog produce disproportionally more eggs than smaller individuals. As the age structure broadens, stocks with more older (larger) fish are likely to have higher reproductive capacity. The narrow slots rebuilt SSB to the largest equilibrium values and were the most effective at broadening age structure. Were reproductive capacity measured in total egg production we would expect the reproductive capacity of the narrow slots to be even larger relative to MSL management than reported.

Management with narrow slots was the most effective strategy for increasing SSB and the abundance of older fish. This may translate into increased population fecundity and, subsequently, resilience. In other species, broad age structures are associated with increased population fecundity (Mehault et al. 2010; Cooper et al. 2013). Increased population fecundity is associated with increased resilience (Le Bris et al. 2018) and truncated age structures with decreased reliance (Stewart 2011; Rouyer et al. 2011). Yet, increased egg production does not predict increased resilience in all species (e.g. Atlantic Cod, Gadus morhua, Stige et al. 2017). 
397 Thus, species-specific analyses are needed to determine which of these metrics is most

398 representative of reproductive capacity for a given species. Despite not evaluating resilience, we 399 report other benefits of harvest slot limits.

401 management: maintaining sustainable harvest levels (biomass) while maximizing catch rates and 402 sustainable harvest levels (Tetzlaff et al. 2013). There is a tradeoff between the narrow slots:

403 while both allow similar magnitudes of removals in biomass, the large-narrow permits the 404 harvest of fewer larger fish (52\% reduction in number harvested) and the small-narrow (19\% 405 reduction in number harvested) increases the opportunity for anglers to harvest more smaller 406 fish. Here the objective of the fishery is important to consider in making management decisions: 407 Should managers permit a larger harvest of smaller fish or a smaller harvest of larger fish? On 408 the other hand, while the large-wide scenario allows the largest biomass removal of the slots in 409 which SSB recovered and resulted in only a $10 \%$ reduction in the number harvested, it was the 410 least effective slot for broadening age structure and equilibrium biomass was reduced relative to 411 MSL. Despite the reduction in terminal SSB, biomass rebuilds to $\mathrm{SSB}_{\text {Target }}$ and $\mathrm{SSB}_{\text {Threshold }}$ more 412 quickly than with MSL management, and age structure broadens. This management approach

413 could be implemented in the short term, allowing stocks to recover, and then modified before the 414 relative abundance decreases. Finally, broadening age structure also is likely to maximize the 415 catch rates of larger/older fish, improving fishing quality which may increase angler satisfaction 416 (Arlinghaus 2006; Gwinn et al. 2015). While changes in daily bag limits, season length, and harvest length limits can reduce 418 harvest, modification to length limits are more effective. Angler behavior responds unpredictably 419 to changes in bag limits and season length. For example, in an Atlantic Salmon Salmo salar 
420 fishery, angler effort did not respond linearly to changes in bag limits (Veinott et al. 2018) but

421 did in a Walleye Sander vitreus fishery (Cox et al. 2002). In a Red Snapper Lutjanus

422 campechanus fishery, a $75 \%$ reduction in season length resulted in a $26 \%$ harvest reduction

423 (Powers and Anson 2016) due to changes in angler behavior. Length limits, in general, are a

424 more effective management tool: a meta-analysis concluded that changing length limits produced

425 greater harvest reductions than bag limits (van Poorten et al. 2013). Finally, recent studies in the

426 region demonstrate angler support for slot limits in Tautog (Schultz et al. 2020) and Striped Bass

427 Morone saxatilis (Murphy et al. 2015) fisheries.

The inclusion of noncompliant behavior incorporates one aspect of a complex suite of

429 potential angler behavioral responses. The varying noncompliance rates we incorporated,

430 informed from other fisheries managed by harvest slot limits (Pierce and Tomcko 1998; Muller

431 et al. 2015), are suggestive of the degree of noncompliance that could be tolerated. Even at $20 \%$

432 noncompliance (slightly larger in magnitude than reported in other fisheries), SSB recovers and

433 age structure broadens in two of our scenarios. But, directed surveys of angler satisfaction, a

434 topic we are currently investigating (Schultz et al. 2020), are more informative of future behavior

435 and could be used for further evaluation. Finally, an unintended consequence of implementing

436 harvest slot management could be a reduction in high-grading, a practice that in the Red Snapper

437 recreational fishery accounts for $84 \%$ of all discarded fish (Garner and Patterson 2015). While

438 Tautog is robust to discards, the practice of high-grading is likely to increase discard mortality.

439 The degree to which harvest slot limits are effective at broadening age structure and

440 rebuilding biomass is dependent on fishery and biological traits. These traits need consideration

441 to generalize our results. Implementing slot limits may not be as effective if age-specific fishing

442 mortalities differ between recreational and commercial sectors due to different regulations or 
443 discard mortalities. Life-history traits are also important to consider in light of management

444 goals. For example, in Summer Flounder Paralichthys dentatus, a sexually dimorphic species in

445 which females grow faster and are larger than males (Morse 1981), slot limits are predicted to

446 reduce females' fishing mortality and meet multiple management goals (Morson et al. 2017). On

447 the other hand, slots could increase female fishing mortality in protogynous hermaphrodites (e.g.

448 serranids, such as Black Sea Bass Centropristis striata) which may decrease the probability of

449 achieving management goals. Another life history trait to consider is age-at-maturity; generally,

450 it is advisable to allow individuals to spawn at least once to try to avoid growth overfishing

451 (Froese 2004). As previously mentioned, harvest slot limits are used in managing multiple

452 marine recreational fisheries, but seemingly, in many cases, without an appropriate level of prior

453 analysis. The value of our case study is not in providing a prescription for reversing age

454 truncation in coastal fisheries, but rather in demonstrating the methods necessary to evaluate this

455 management technique as a potential solution.

Our results are constrained by the parameterization of constant removal biomass and

457 constant fishery selectivity in the forward population simulations. These are reasonable

458 assumptions as the stock is managed with a target removal value and with size limits which

459 define the selectivity curve. As the stock recovers, fishing mortality will decrease if removals are

460 constant. But as older fish become more abundant, the number that die due to discard mortality

461 and noncompliant harvest is expected to increase. An alternative to our approach of constant

462 removals in the forecast model would be to maintain constant fishing mortality and predict future

463 changes in removals. If fishing mortality were constant, the biomass of removals would increase,

464 particularly in the scenarios for which the strongest recoveries are predicted. The increase in

465 removals would ultimately dampen the terminal SSB estimates and may reduce the broadening 
466 of the age structure. Either of these approaches, constant removals or constant fishing mortality,

467 are an approximation of a future scenario; in practice, stock assessments are updated every five

468 years and the management is modified to reflect changes in removals, fishing mortality, and

469 selectivity.

In this study, removal biomass varied among the scenarios analyzed. Estimated removal

471 biomass is influenced by slot breadth, slot location, angler behavior, and discard mortality.

472 Recreational fisheries are generally not managed by total allowable catch, thus setting a target

473 removal biomass and estimating the performance of a slot would not be relevant to the current

474 management infrastructure. By allowing the removal biomass to vary with each slot, angler

475 behavior, and discard mortality, we have incorporated a level of management-relevant realism 476 into the analysis.

Modifying fishery selectivity with harvest slot limits can broaden the age structure and

478 restore the SSB of a species that is age truncated and overfished more quickly than with MSL

479 management. The recovery is realized, in part, by reduced harvest biomass, but the number of

480 fish harvested need not be reduced by a similar magnitude. For species with a recreational

481 harvest component, the opportunity to harvest can be preserved (albeit at a lower biomass and

482 redirected to a prescribed size range of fish). We have shown that the actual ability to restore

483 SSB depends on the median size of harvest slot and slot breadth, but can be robust to high levels

484 of noncompliance. The largest relative increases in the abundance of old fish occurred within the

485 first 10 years of harvest slot management, owing to the slower recovery with MSL management.

486 Harvest slot limits belong in the coastal fisheries manager toolbox and the modeling capacity

487 (data and code) to evaluate slots exists for many fisheries (as evidenced by our example). Case

488 studies are important for evaluating alternative management strategies: we provide new methods 
to parameterize projection models with harvest slot removals, fisheries selectivity, and noncompliance and show that slot removals alone is not a sufficient predictor of management success. Thus, implementing harvest slots without projecting their efficacy may not rebuild SSB.

492 Perhaps not surprisingly, harvest slots are unlikely to be 'set it and forget it' management tools but deserve more real-world evaluation and experimentation with actively managed fish stocks.

$<$ A $>$ Acknowledgments

We would like to thank ASMFC, Chris Legault, and the Tautog technical committee for technical assistance, insight, and guidance. The CT DEEP and NY DEC provided data and 497 technical expertise, and the crews of the research vessels collected data for many years. The 498 Wildlife and Sport Fish Restoration Program funded the CT LISTS and the Atlantic Coastal 499 Cooperative Statistics Program supported fisheries data collection. Richard McBride, Mike 500 Allen, Chris Legault, and anonymous reviewers provided valuable feedback on this manuscript. 501 The CT Marine Volunteer Angler Survey Program (and its participants) and the American 502 Littoral Society provided fishery dependent data. Virge Kask developed the schematic. Funding 503 for this work was provided by LVAO and Connecticut Sea Grant, University of Connecticut 504 through Award No. NA14OAR4170086, Project Number R/LR-27.

$505<\mathrm{A}>$ References

Anderson, C. N. K., C. Hsieh, S. A. Sandin, R. Hewitt, A. Hollowed, J. Beddington, R. M. May, and G. Sugihara. 2008. Why fishing magnifies fluctuations in fish abundance. Nature 452:835-839.

Arlinghaus, R. 2006. On the Apparently Striking Disconnect between Motivation and Satisfaction in Recreational Fishing: The Case of Catch Orientation of German Anglers. North American Journal of Fisheries Management 26:592-605.

Arlinghaus, R., U. Dieckmann, and S. Matsumura. 2010. The conservation and fishery benefits of protecting large pike (Esox lucius L.) by harvest regulations in recreational fishing. Biological Conservation 143:1444-1459.

Armstrong, M., P. Hood, M. Murphy, and R. Muller. 1996. A stock assessment of permit, Trachinotus falcatus, in Florida waters. Florida Department of Environmental Protection, Florida Marine Research Institute, St. Petersburg, FL.

ASMFC. 2013. Interstate Fishery Management Plan for Black Drum. Page 83. Atlantic States Marine Fisheries Commission. Available at: http://www.asmfc.org/uploads/file/BlackDrumInterstateFMP_June2013.pdf.

ASMFC. 2015. Tautog Benchmark Stock Assessment and Peer Review Reports. Pages 1-283. Available at: http://www.asmfc.org/uploads/file//54eccd8cTautogStockAssessment_PeerReviewReport _Feb2015.pdf. 
ASMFC. 2016. Atlantic States Marine Fisheries Commission 2016 Tautog Stock Assessment Update. Atlantic States Marine Fisheries Commission. Available at: https://www.asmfc.org/uploads/file/589e1d3f2016TautogAssessmentUpdate_Oct2016.pd f.

ASMFC. 2017. Amendment 1 to the Interstate Fishery Management Plan for Tautog. Atlantic States Marine Fisheries Commission. Available at: https://www.asmfc.org/files/PublicInput/Tautog_DraftAmendment1_PublicComment_M ay2017.pdf.

Barneche, D. R., D. R. Robertson, C. R. White, and D. J. Marshall. 2018. Fish reproductiveenergy output increases disproportionately with body size. Science 360:642-645.

Barnett, L. A. K., T. A. Branch, R. A. Ranasinghe, and T. E. Essington. 2017. Old-Growth Fishes Become Scarce Under Fishing. Current Biology 27:2843-2848.

Berkeley, S. A. 2006. Pacific Rockfish Management: are we circling the wagons around the wrong paradigm? Bulletin of Marine Science 78:655-668.

Berkeley, S. A., C. Chapman, and S. M. Sogard. 2004. Maternal Age as a Determinant of Larval Growth and Survival in a Marine Fish, Sebastes melanops. Ecology 85:1258-1264.

Botsford, L. W., M. D. Holland, J. C. Field, and A. Hastings. 2014. Cohort resonance: a significant component of fluctuations in recruitment, egg production, and catch of fished populations. ICES Journal of Marine Science 71:2158-2170.

Brodziak, J. 2009. Using Satellite Data to Improve Short-Term Recruitment Predictions for Marine Fish Stocks. NOAA National Marine Fisheries Service, PIFSC Internal Report IR-09-015, Pacific Islands Fisheries Science Center. Available at: https://www.nasa.gov/sites/default/files/files/EF-ShortTerm_Recruitment_Predictions_for_Marine_Fish_Stocks.pdf.

Carr, J. P., and L. Kaufman. 2009. Estimating the importance of maternal age, size, and spawning experience to recruitment of Atlantic cod (Gadus morhua). Biological Conservation 142:477-487.

Chenoweth, S. 1963. Spawning and fecundity of the Tautog, Tautoga onitis. M.S. thesis., University Of Rhode Island, North Kingston, RI.

Conn, P. B., E. H. Williams, and K. W. Shertzer. 2010. When can we reliably estimate the productivity of fish stocks? Canadian Journal of Fisheries and Aquatic Sciences 67:511523. NRC Research Press.

Cooper, R. A. 1967. Age and Growth of the Tautog, Tautoga onitis (Linnaeus), from Rhode Island. Transactions of the American Fisheries Society 96:134-142.

Cooper, W. T., L. R. Barbieri, M. D. Murphy, and S. K. Lowerre-Barbieri. 2013. Assessing stock reproductive potential in species with indeterminate fecundity: Effects of age truncation and size-dependent reproductive timing. Fisheries Research 138:31-41.

Cox, S. P., T. D. Beard, and C. Walters. 2002. Harvest Control in Open-Access Sport Fisheries: Hot Rod or Asleep at the Reel? Bulletin of Marine Science 70:749-761.

CT Department of Energy and Environmental Protection. 2016. JOB 5: Marine Finfish Survey: Long Island Sound Trawl Survey. CT DEEP. Available at: https://www.ct.gov/deep/lib/deep/fishing/publications/2016_Long_Island_Sound_Trawl_ Survey.pdf.

Dippold, D. A., R. T. Leaf, and M. S. Peterson. 2016. Evaluating Management Regimes using Per-Recruit Models and Relative Stock Density for Mississippi's Spotted Seatrout. North American Journal of Fisheries Management 36:1178-1189. 
Fauconnet, L., and M.-J. Rochet. 2016. Fishing selectivity as an instrument to reach management objectives in an ecosystem approach to fisheries. Marine Policy 64:46-54.

FL FWCC. 2019. Recreational Regulations. Available at: http://myfwc.com/fishing/saltwater/recreational/.

Francis, R. I. C. C. 2011. Data weighting in statistical fisheries stock assessment models. Canadian Journal of Fisheries and Aquatic Sciences 68:1124-1138.

Froese, R. 2004. Keep it simple: three indicators to deal with overfishing. Fish and Fisheries 5:86-91.

Garner, S. B., and W. F. Patterson. 2015. Direct observation of fishing effort, catch, and discard rates of charter boats targeting reef fishes in the northern Gulf of Mexico. Fishery Bulletin 113:157-166.

Garner, S. B., W. F. Patterson, and C. E. Porch. 2017. Experimental assessment of circle vs. J hook performance and selectivity in the northern Gulf of Mexico recreational reef fish fishery. ICES Journal of Marine Science 74:1437-1447.

Gerritsen, H. D., D. McGrath, and C. Lordan. 2006. A simple method for comparing age-length keys reveals significant regional differences within a single stock of haddock (Melanogrammus aeglefinus). ICES Journal of Marine Science 63:1096-1100.

GMFMC. 2020. Federal Fishing Regulations, Gulf of Mexico Fishery Management Council. Available at: https://gulfcouncil.org/fishing-regulations/federal/.

Gwinn, D. C., M. S. Allen, F. D. Johnston, P. Brown, C. R. Todd, and R. Arlinghaus. 2015. Rethinking length-based fisheries regulations: the value of protecting old and large fish with harvest slots. Fish and Fisheries 16:259-281.

Hixon, M. A., D. W. Johnson, and S. M. Sogard. 2014. BOFFFFs: on the importance of conserving old-growth age structure in fishery populations. ICES Journal of Marine Science 71:2171-2185.

Kindsvater, H. K., and E. P. Palkovacs. 2017. Predicting Eco-evolutionary Impacts of Fishing on Body Size and Trophic Role of Atlantic Cod. Copeia 105:475-482.

LaPlante, L. H., and E. T. Schultz. 2007. Annual Fecundity of Tautog in Long Island Sound: Size Effects and Long-Term Changes in a Harvested Population. Transactions of the American Fisheries Society 136:1520-1533.

Le Bris, A., K. E. Mills, R. A. Wahle, Y. Chen, M. A. Alexander, A. J. Allyn, J. G. Schuetz, J. D. Scott, and A. J. Pershing. 2018. Climate vulnerability and resilience in the most valuable North American fishery. Proceedings of the National Academy of Sciences 115:1831-1836.

Leaf, R. T., L. Rogers-Bennett, and Y. Jiao. 2008. Exploring the Use of a Size-Based Egg-perRecruit Model for the Red Abalone Fishery in California. North American Journal of Fisheries Management 28:1638-1647.

Lee, H.-H., M. N. Maunder, K. R. Piner, and R. D. Methot. 2012. Can steepness of the stockrecruitment relationship be estimated in fishery stock assessment models? Fisheries Research 125-126:254-261.

Legault, C. M., and V. R. Restrepo. 1999. A Flexible Forward Age-Structured Assessment Program. ICCAT Coll. Vol. Sci. Pap. 49(2):246-253.

Mangel, M., A. D. MacCall, J. Brodziak, E. J. Dick, R. E. Forrest, R. Pourzand, and S. Ralston. 2013. A perspective on steepness, reference points, and stock assessment. Canadian Journal of Fisheries and Aquatic Sciences 70:930-940. 
Marshall, D. J., S. S. Heppell, S. B. Munch, and R. R. Warner. 2010. The relationship between maternal phenotype and offspring quality: Do older mothers really produce the best offspring? Ecology 91:2862-2873.

McBride, R. S., S. Somarakis, G. R. Fitzhugh, A. Albert, N. A. Yaragina, M. J. Wuenschel, A. Alonso-Fernández, and G. Basilone. 2015. Energy acquisition and allocation to egg production in relation to fish reproductive strategies. Fish and Fisheries 16:23-57.

McCandless, C. T., and C. Grahn. 2014. Standardized indices of abundance for Smooth Dogfish, Mustelus canis, from the Peconic Bay Small Mesh Trawl Survey conducted by the New York State Department of Environmental Conservation. SEDAR39-DW-13, North Charleston, SC.

MD DNR. 2019. Maryland Guide to Fishing and Crabbing 2019. Available at: http://www.eregulations.com/wp-content/uploads/2019/01/19MDFW-LR8.pdf.

Mehault, S., R. Domínguez-Petit, S. Cerviño, and F. Saborido-Rey. 2010. Variability in total egg production and implications for management of the southern stock of European hake. Fisheries Research 104:111-122.

Morse, W. W. 1981. Reproduction of the summer flounder, Paralichthys dentatus (L.). Journal of Fish Biology 19:189-203.

Morson, J. M., D. Munroe, R. Harner, and R. Marshall. 2017. Evaluating the Potential for a SexBalanced Harvest Approach in the Recreational Summer Flounder Fishery. North American Journal of Fisheries Management 37:1231-1242.

Muller, R. G., A. A. Trotter, and P. W. Stevens. 2015. The 2015 Stock Assessment Update of Common Snook, Centropomus undecimalis. IHR 2015-004.

Murphy, R. D., S. B. Scyphers, and J. H. Grabowski. 2015. Assessing Fishers' Support of Striped Bass Management Strategies. PLoS ONE 10:e0136412.

NOAA Fisheries Toolbox. 2014. Age Structured Assessment Program, Version 3.0.16. Available at: https://www.nefsc.noaa.gov/nft.

NOAA Fisheries Toolbox. 2018. Age Structured Projection Model, Version 4.3.0. Available at: https://www.nefsc.noaa.gov/nft.

NYS DEC. 2019. Recreational Saltwater Fishing Limits. Available at: https://www.dec.ny.gov/docs/fish_marine_pdf/fishlimitsfish.pdf.

Palumbi, S. R. 2004. Fisheries science: Why mothers matter. Nature 430:621-622.

personal communication from the National Marine Fisheries Service, Fisheries Statistics Division. 2016, September 1. queries. page. Available at: https://ST/recreationalfisheries/data-and-documentation/queries/index.

Pierce, R. B. 2010. Long-Term Evaluations of Length Limit Regulations for Northern Pike in Minnesota. North American Journal of Fisheries Management 30:412-432.

Pierce, R. B., and C. M. Tomcko. 1998. Angler Noncompliance with Slot Length Limits for Northern Pike in Five Small Minnesota Lakes. North American Journal of Fisheries Management 18:720-724.

van Poorten, B. T., S. P. Cox, and A. B. Cooper. 2013. Efficacy of Harvest and Minimum Size Limit Regulations for Controlling Short-term Harvest in Recreational Fisheries. Fisheries Management and Ecology 20:258-267.

Powers, S. P., and K. Anson. 2016. Estimating Recreational Effort in the Gulf of Mexico Red Snapper Fishery Using Boat Ramp Cameras: Reduction in Federal Season Length Does Not Proportionally Reduce Catch. North American Journal of Fisheries Management 36:1156-1166. 
662

663

664

665

666

667

668

669

670

671

672

673

674

675

676

677

678

679

680

681

682

683

684

685

686

687

704

705

706

Powers, S. P., C. L. Hightower, J. Marcus Drymon, and M. W. Johnson. 2012. Age composition and distribution of red drum (Sciaenops ocellatus) in offshore waters of the north central Gulf of Mexico: an evaluation of a stock under a federal harvest moratorium. Fishery Bulletin 110:283-292.

Rouyer, T., G. Ottersen, J. M. Durant, M. Hidalgo, D. ø. Hjermann, J. Persson, L. Chr. Stige, and N. Chr. Stenseth. 2011. Shifting dynamic forces in fish stock fluctuations triggered by age truncation? Global Change Biology 17:3046-3057.

Schmidtke, M., C. Kalinowsky, S. Arnott, S. Poland, and D. Lipton. 2017. Review of the Atlantic States Marine Fisheries Commission Fishery Management Plan for Spotted Seatrout (Cynoscion nebulosus). Available at: http://www.asmfc.org/uploads/file/5a0f626cspottedseatroutFMPReview2017.pdf.

Schultz, E. T., Z. Chen, P. Liu, S. Swallow, and J. M. Kasper. 2020. Bio-economic Outcomes under Alternative Management Strategies with Human Choice and Behavior: Modeling Tautog and Anglers' Preferences. Report of survey and preliminary analysis of results. Available at: https://opencommons.uconn.edu/eebcondense_articles/47/.

SEDAR. 2020. Atlantic Menhaden Benchmark Stock Assessment Report. Page 691. SEDAR, SEDAR 69, North Charleston SC. Available at: http://sedarweb.org/sedar-69.

Silliman, R. P., and J. S. Gutsell. 1958. Experimental Exploitation of Fish Populations. Fishery Bulletin 58:215-252.

Simpson, D. G. 1999. A Study of Marine Recreational Fisheries in Connecticut. F54R Annual Report, CT DEP Federal Aid to Sportfish Restoration.

Sogard, S. M., S. A. Berkeley, and R. Fisher. 2008. Maternal effects in rockfishes Sebastes spp.: a comparison among species. Marine Ecology Progress Series 360:227-236.

Stewart, J. 2011. Evidence of age-class truncation in some exploited marine fish populations in New South Wales, Australia. Fisheries Research 108:209-213.

Stige, L. C., N. A. Yaragina, Ø. Langangen, B. Bogstad, N. C. Stenseth, and G. Ottersen. 2017. Effect of a fish stock's demographic structure on offspring survival and sensitivity to climate. Proceedings of the National Academy of Sciences 114:1347-1352.

Sustainable Fisheries Act of the Magnuson-Stevens Fishery Conservation and Management Act. 1996. Silver Spring: U.S. Department of Commerce, National Oceanic and Atmospheric Administration, National Marine Fisheries Service. Available at: https://www.fisheries.noaa.gov/resource/document/magnuson-stevens-fisheryconservation-and-management-act.

Tetzlaff, J. C., W. E. Pine, M. S. Allen, and R. N. Ahrens. 2013. Effectiveness of Size Limits and Bag Limits for Managing Recreational Fisheries: A Case Study of the Gulf of Mexico Recreational Gag Fishery. Bulletin of Marine Science 89:483-502.

Tiainen, J., M. Olin, H. Lehtonen, K. Nyberg, and J. Ruuhijärvi. 2017. The capability of harvestable slot-length limit regulation in conserving large and old northern pike (Esox lucius). Boreal Environment Research 22:169-186.

Vaughan, D. S., and J. T. Carmichael. 2002. Estimating Improvement in Spawning Potential Ratios for South Atlantic Red Drum through Bag and Size Limit Regulations. North American Journal of Fisheries Management 22:895-906.

Veinott, G., L. Pike, and A. M. Variyath. 2018. Response of Anglers to Less-Restrictive Harvest Controls in a Recreational Atlantic Salmon Fishery. North American Journal of Fisheries Management 38:210-222. 
Venables, W. N., and B. D. Ripley. 2002. Modern Applied Statistics with S4th edition. Springer, New York. Available at: http://www.stats.ox.ac.uk/pub/MASS4.

WA DFW. 2019. Sport Fishing Rules Pamphlet Corrections and Updates/Clarifications. Available at: https://wdfw.wa.gov/sites/default/files/publications/01998/wdfw01998.pdf. 
717 TABLE 1: Data sources and their contribution to the Tautog stock assessment model for Long

718 Island Sound. Surveys were either fishery-independent (I) or fishery-dependent (D). Survey

719 names are abbreviated: Long Island Sound Trawl Survey (LISTS), Peconic Bay Small Mesh

720 Trawl Survey (PBSMTS), Western Long Island Sound Juvenile Abundance Survey (WLISJAS),

721 Marine Recreational Fisheries Statistics Survey (MRFSS), Marine Recreational Information

722 Program (MRIP), New York party (head) boat survey (NYHB), Connecticut Marine Volunteer

723 Angler Survey Program (CTVAS), and the American Littoral Society (ALS).

\begin{tabular}{|c|c|c|c|c|c|c|c|c|c|c|c|}
\hline Source & Years & $\begin{array}{c}\text { Survey } \\
\text { Type }\end{array}$ & $\begin{array}{l}\text { Harvest } \\
\text { Length }\end{array}$ & $\begin{array}{l}\text { Discard } \\
\text { Lengths }\end{array}$ & Length & Age & Weight & Sex & $\begin{array}{l}\text { Catch } \\
(\mathrm{N})\end{array}$ & $\begin{array}{l}\text { Abundance } \\
\text { Index }\end{array}$ & $\begin{array}{l}\text { Effort } \\
\text { Index }\end{array}$ \\
\hline LISTS & $1984-2015$ & I & & & $\checkmark$ & $\checkmark$ & $\checkmark$ & $\checkmark$ & & $\checkmark$ & \\
\hline PBSMTS & $1987-2015^{\mathrm{a}}$ & I & & & $\checkmark$ & $\checkmark$ & & & & $\checkmark$ & \\
\hline WLISJAS & $1995-2015^{b}$ & I & & & $\checkmark$ & $\checkmark$ & & & & $\checkmark$ & \\
\hline MRFSS & 1984-2003 & $\mathrm{D}$ & $\checkmark$ & & & & & & $\checkmark$ & & $\checkmark$ \\
\hline MRIP & $2004-2015$ & $\mathrm{D}$ & $\checkmark$ & $\checkmark$ & & & & & $\checkmark$ & & $\checkmark$ \\
\hline NYHB & $1995-2014^{\mathrm{c}}$ & $\mathrm{D}$ & $\checkmark$ & $\checkmark$ & & $\checkmark$ & & & & & \\
\hline CTVAS & $1997-2015$ & $\mathrm{D}$ & $\checkmark$ & $\checkmark$ & & & & & & & \\
\hline ALS & $1987-2015$ & $\mathrm{D}$ & & $\checkmark$ & & 20 & & & & & \\
\hline
\end{tabular}

724 aexcept years 2005, 2005, 2008; bexcept years 1985, 1994, 2009; cexcept years 2000-2007 
726 TABLE 2: Model parameters and derived quantities, description, and value (when appropriate)

727 used in the stock assessment and population simulation model for Tautog in Long Island Sound.

728 The single logistic model was indexed by selectivity block $(b=1-4)$ for the stock assessment and

729 was constant (no subscript) for the minimum size limit (MSL) scenario used in the population

730 simulations.

\begin{tabular}{|c|c|c|}
\hline Parameter/derived quantities & Description & Value (s) \\
\hline$B$ & Selectivity block & $1,2,3,4$ \\
\hline$F_{D}$ & Discard mortality rate & 0.025 \\
\hline$M_{a}$ & Natural Mortality & 0.15 \\
\hline$P_{M A, a}$ & Proportion maturity-at-age & $0,0,0.8,1, \ldots 1$ \\
\hline$P_{S S B}$ & Proportion of year prior to spawning & 0.42 \\
\hline$A$ & Maximum age (years) & 16 \\
\hline$A$ & Age (years) & \\
\hline$T$ & Time (years) & \\
\hline$C_{L}$ & Catch-at-length & \\
\hline$P_{H, L}$ & Proportion harvested-at-length & \\
\hline$P_{a}$ & Proportion of removals-at-age & \\
\hline$R_{a}$ & Removals-at-age & \\
\hline$R_{B}$ & Removal biomass & \\
\hline$R_{L}$ & Removals-at-length & \\
\hline$R_{N}$ & Number of fish removed & \\
\hline$W_{L}$ & Weight-at-length & \\
\hline$\alpha$ & $\begin{array}{l}\text { single logistic midpoint, subscripted with values } \\
\text { of } b \text { for stock assessment or no subscript in the } \\
\text { population simulation of MSL }\end{array}$ & \\
\hline$\beta$ & $\begin{array}{l}\text { single logistic slope, subscripted with values of } b \\
\text { for stock assessment or no subscript in the } \\
\text { population simulation of MSL }\end{array}$ & \\
\hline$\alpha_{z}$ & $\begin{array}{l}\text { ascending }(z=1) \text { and descending }(z=2) \text { of the } \\
\text { midpoint of the double logistic }\end{array}$ & \\
\hline$\beta_{z}$ & $\begin{array}{l}\text { ascending }(z=1) \text { and descending }(z=2) \text { of the } \\
\text { slope of the double logistic }\end{array}$ & \\
\hline$F_{t, a}$ & Fishing mortality & \\
\hline Fmult $_{t}$ & Fully selected fishing mortality & \\
\hline $\log _{-} R d e v_{t}$ & Lognormal recruitment deviations & \\
\hline
\end{tabular}




\begin{tabular}{ll}
$N_{t, a}$ & Population abundance-at-age \\
$R_{t}$ & Expected recruitment \\
$S_{b, a}$ & Selectivity-at-age \\
$S P R_{0}$ & Unexploited spawners per recruit \\
$S S B_{0}$ & Unexploited spawning stock biomass \\
$S S B$ & Spawning stock biomass \\
$W_{t, a}$ & Weight-at-age \\
$Z_{t, a}$ & Total mortality-at-age \\
\hline
\end{tabular}

731 
732 TABLE 3: Management scenarios for Tautog in Long Island Sound. Each slot scenario was

733 evaluated with full compliance and $10 \%$ or $20 \%$ noncompliance (NC) with the upper slot limit.

734 Removals in biomass (B), 1,000s of fish (N), and the percent change compared to minimum size

735 limit (MSL) management. Removals were constant in the forward population simulations and

736 based on past fishery performance.

\begin{tabular}{lccll}
\hline Scenario & $\begin{array}{c}\mathrm{B} \\
(\mathrm{mt})\end{array}$ & $\begin{array}{c}\mathrm{N} \\
(1,000 \mathrm{~s})\end{array}$ & $\begin{array}{l}\text { Percent } \\
\text { change }(\mathrm{B})\end{array}$ & $\begin{array}{c}\text { Percent } \\
\text { change }(\mathrm{N})\end{array}$ \\
\hline MSL & 418 & 236 & & \\
Small-narrow & & & & \\
Compliant & 220 & 191 & $53 \%$ & $81 \%$ \\
$10 \%$ NC & 257 & 208 & $61 \%$ & $88 \%$ \\
20\% NC & 294 & 224 & $70 \%$ & $95 \%$ \\
Small-wide & & & & \\
Compliant & 450 & 401 & $108 \%$ & $170 \%$ \\
$10 \%$ NC & 477 & 412 & $114 \%$ & $175 \%$ \\
20\% NC & 503 & 422 & $120 \%$ & $179 \%$ \\
Large-narrow & & & & \\
Compliant & 188 & 113 & $45 \%$ & $48 \%$ \\
10\% NC & 207 & 120 & $49 \%$ & $51 \%$ \\
20\% NC & 225 & 127 & $54 \%$ & $54 \%$ \\
Large-wide & & & & \\
Compliant & 348 & 213 & $83 \%$ & $90 \%$ \\
$10 \%$ NC & 357 & 216 & $85 \%$ & $92 \%$ \\
20\% NC & 366 & 219 & $88 \%$ & $93 \%$ \\
\hline
\end{tabular}


739 TABLE 4: Time (years) to reach spawning stock biomass (SSB) biological reference points

$740 \quad\left(\mathrm{SSB}_{\text {Threshold }}\right.$ and $\left.\mathrm{SSB}_{\text {Target }}\right)$ for each management strategy (slot or minimum size limit, MSL) for

741 Tautog in Long Island Sound. Slot scenarios include compliance with the upper slot limit as well

742 as $10 \%$ and $20 \%$ noncompliance (NC) with the upper slot limit. The year that SSB is largest

743 relative to SSB with MSL management (max relative difference) and the year in which SSB

744 reaches equilibrium are also included. Median and 5th/95th percentiles (confidence limits) are

745 provided. Scenarios in which SSB crashed are indicated (-).

\begin{tabular}{lllll}
\hline Scenario & $\begin{array}{c}\text { Year SSB } \geq \\
\mathrm{SSBB}_{\text {Target }}\end{array}$ & $\begin{array}{c}\text { Year SSB } \geq \\
\mathrm{SSB}_{\text {Threshold }}\end{array}$ & $\begin{array}{c}\text { Year } \\
\text { equilibrium }\end{array}$ & $\begin{array}{c}\text { Year max } \\
\text { relative change }\end{array}$ \\
\hline MSL & $22(9,-)$ & $9(2,23)$ & $26(22,31)$ & - \\
Small-narrow & & & & \\
Compliant & $7(4,11)$ & $4(2,6)$ & $20(19,21)$ & $12(12,13)$ \\
$10 \%$ NC & $8(4,14)$ & $4(2,7)$ & $19(19,20)$ & $12(11,13)$ \\
20\% NC & $10(5,23)$ & $5(2,9)$ & $19(19,20)$ & $10(10,11)$ \\
Small-wide & & & & \\
Compliant & $-(-,-)$ & $-(3,-)$ & $-(-,-)$ & $-(-,-)$ \\
$10 \%$ NC & $-(-,-)$ & $-(4,-)$ & $-(-,-)$ & $-(-,-)$ \\
20\% NC & $-(-,-)$ & $-(-,-)$ & $-(-,-)$ & $-(-,-)$ \\
Large-narrow & & & & $14(14,14)$ \\
Compliant & $6(4,9)$ & $3(2,5)$ & $21(19,22)$ & $14(14,14)$ \\
$10 \%$ NC & $6(4,9)$ & $3(2,6)$ & $21(19,22)$ & $14(14)$ \\
20\% NC & $7(4,10)$ & $4(2,6)$ & $21(19,22)$ & $14(14,14)$ \\
Large-wide & & & & \\
Compliant & $16(6,-)$ & $6(2,16)$ & $19(18,21)$ & $9(8,10)$ \\
$10 \%$ NC & $19(7,-)$ & $7(2,19)$ & $19(18,21)$ & $8(8,8)$ \\
$20 \%$ NC & $25(7,-)$ & $7(2,24)$ & $19(17,21)$ & $7(7,7)$ \\
\hline
\end{tabular}


Appendices: Broadening Age Structure

\section{Appendix 1: Data}

2 Catch-at-length. - Gamma distributions were fit to both the harvest-at-length and discard-at-

3 length observations for each selectivity block using a Bayesian model and a random year effect

4 variable. Gamma distribution was selected after fitting harvest and discard length observations

5 independently to log-normal, normal, and gamma distributions using the fitdistr function in the

6 MASS package (Venables and Ripley 2002). Resulting models were tested for goodness of fit

7 using a one-sample Kolmogorov-Smirnov (ks.test). For harvest lengths, the gamma distribution

8 had the lowest $\mathrm{D}$ value. While the normal distribution had the lowest $\mathrm{D}$ value for discard lengths,

9 the gamma distribution (which had the second-lowest D value) was selected to avoid predicting

10 negative lengths with the normal distribution. This analysis was performed in $\mathrm{R}$ using the R2jags

11 package (Su and Masanao Yajima 2015). Posterior distributions were estimated with JAGS

12 (Plummer 2003) using a Gibbs sampler. Vague priors were used and checked against posterior

13 distributions to ensure that priors were flat in the region of the posterior estimate. Estimates were

14 drawn from 15,000 iterations, using a burn-in period of 5,000 and 3 chains.

15 Model code:

16 ("model \{

17 for $(\mathrm{j}$ in $1: 4)\{$

18 b.year[j] $\sim$ dnorm(mu.year, tau.year)

19

20

21

22

for(i in 1:n.obs) \{

$\mathrm{y}[\mathrm{i}] \sim \operatorname{dgamma}(\mathrm{a}[\mathrm{i}], \mathrm{b}[\mathrm{i}])$

$\mathrm{a}[\mathrm{i}]<-\left((\mathrm{mu}[\mathrm{i}])^{\wedge} 2\right) / \operatorname{sigma}^{\wedge} 2$

$\mathrm{b}[\mathrm{i}]<-(\mathrm{mu}[\mathrm{i}]) / \operatorname{sigma}^{\wedge} 2$

$\log (\mathrm{mu}[\mathrm{i}])<-$ b.block$[$ block$[\mathrm{i}]]$

\}

sigma $\sim \operatorname{dgamma}(0.001,0.001)$

mu.block $\sim \operatorname{dnorm}(0,0.001)$

tau.block $\sim$ dgamma $(0.0001,0.0001)$

\}$\left.^{\prime \prime}\right)$

In the last selectivity block, harvest of undersized fish represented $8 \%$ of the observed

31 harvest while the release of fish over the minimum size represents $0.3 \%$ of the observed discards. 
32 As such, sampling from gamma distributions allowed for the harvest of undersized fish, but not

33 for the release of fish over the minimum size.

34 Catch length-at-age.- The last major modification in data preparation was the procedure to 35 estimate catch length-at-age. The ASMFC assessment borrowed aging data from neighboring 36 states, as there were not enough Long Island Sound-specific age samples to develop a robust age-

37 length key. This assessment implemented a multinomial approach (Gerritsen et al. 2006)

38 developed with the nnet package in R (Venables and Ripley 2002) to facilitate the use of Long

39 Island Sound- and selectivity block-specific samples (Table 1). The multinomial coefficients

40 (Table A.1) were used to predict the probability of length-at-age using the predict function in R.

41 Removals-at-age was the probably of length-at-age multiplied by the catch-at-length. Length-at-

42 age was estimated independently for each selectivity block, using a maximum age of 16 years.

43 Weight-at-length. - Catch-weight-at-length was estimated independently for each selectivity

44 block (Table A.2). Weight-at-length was calculated by fitting a linear model to log-transformed

45 observations from the CT Long Island Sound Trawl Survey and correcting for back-

46 transformation bias (Sprugel 1983) using the FSA package in R (Ogle et al. 2020; R Core Team

47 2020) when estimating the weight-at-age for the mean catch-length-at-age. Spawning stock

48 biomass-weight-at-age was estimated with the von Bertalanffy growth model (Table A.2) using

49 the growth function in the FSA package (Ogle et al. 2020). Weight-at-age was then estimated for 50 mean length-at-age using the same procedure as for the catch-weight-at-length.

51 Commercial harvest. - Commercial harvest was treated in this assessment as it was treated in

52 the ASMFC Tautog stock assessment for Long Island Sound (ASMFC 2016). In brief, the 53 commercial harvest was included in the total removals because it is a relatively small proportion 
Appendices: Broadening Age Structure

54 of the harvest ( $\sim 10 \%$ annually) and because commercial regulations are similar to recreational

55 regulations.

\section{Appendix 2: Stock characteristics}

Model Parameterization.-Several modifications were made to how these data were prepared for this stock assessment versus the ASMFC assessment (ASMFC 2016). The age-plus group for the current analysis was changed to ages $16+$ from the $12+$ age group used in the ASMFC assessment. This change was made to incorporate all ages of growth and to minimize the loss of reproductive potential in a $12+$ age group, which would underestimate the impact of harvest slots. As with the ASMFC assessment, this assessment used for fishery selectivity blocks.

Length-at-age and weight-at-length were estimated independently for each selectivity block because some years had small sample sizes, preliminary analysis indicated changes in growth over time, the previously reported size-truncation (LaPlante and Schultz 2007) and age truncation reported herein.

Some parameters were modified from the ASMFC assessment while others remained the same. The following parameters were not modified: years of assessment (1984-2015), number of fleets (1), number of surveys (4), the number of weight-at-age matrices (2, one for catch weightat-age and one for spawning stock biomass-weight-at-age), start age of average F calculation (8), and estimating selectivity as a single logistic. The following parameters were recalculated because the age plus group was expanded from 12 in the ASMFC assessment to 16 in the current contribution: catch-at-age, weight-at-age matrices, removals-at-age, total weight of removals.

The last major departure from the ASMFC assessment was that the stock-recruit relationship was not estimated (fixed at 1), so biological reference points are spawning biomass per recruit (SPR) based. Here, $\mathrm{F}_{40 \% \mathrm{SPR}}$ is the $\mathrm{F}_{\text {Target }}$ and $\mathrm{F}_{30 \% \mathrm{SPR}}$ is the $\mathrm{F}_{\text {Threshold. }}$ 
$<$ A $>$ Methods

The removal biomass that results in the median $\mathrm{SSB}$ to be equivalent to $\mathrm{SSB}_{\text {Target }}$ after 10

81 simulation model used for all other projections, using the MSL fishery selectivity curve. This

82 benchmark was chosen for compliance with stock rebuilding criteria under federal fisheries

83 management legislation (Sustainable Fisheries Act of the Magnuson-Stevens Fishery

84 Conservation and Management Act 1996). The removal value estimated by the reiterative

85 process was then utilized in the forward population simulation model.

86

$<$ A $>$ Results

A harvest of 352 metric tons $(27 \%$ harvest reduction, compared to the current management which targets a $20.3 \%$ harvest reduction) would rebuild the stock within 10 years.

When managed with the MSA required reduction, SSB recovers relative to the current

management approach (Figure A1) and age structure broadens (Figure A2). But this management approach is not as effective at broadening age structure as harvest slot limits.

\section{References}

ASMFC. 2016. Atlantic States Marine Fisheries Commission 2016 Tautog Stock Assessment Update. Atlantic States Marine Fisheries Commission.

Gerritsen, H. D., D. McGrath, and C. Lordan. 2006. A simple method for comparing age-length keys reveals significant regional differences within a single stock of haddock (Melanogrammus aeglefinus). ICES Journal of Marine Science 63:1096-1100.

LaPlante, L. H., and E. T. Schultz. 2007. Annual Fecundity of Tautog in Long Island Sound: Size Effects and Long-Term Changes in a Harvested Population. Transactions of the American Fisheries Society 136:1520-1533.

Ogle, D. H., P. Wheeler, and A. Dinno. 2020. FSA: Fisheries Stock Analysis.

Plummer, M. 2003. JAGS: A program for analysis of Bayesian graphical models using Gibbs sampling. Working Papers:8.

R Core Team. 2020. R: A language and environment for statistical computing. R Foundation for Statistical Computing, Vienna, Austria. 
Appendices: Broadening Age Structure

106 Sprugel, D. G. 1983. Correcting for Bias in Log-Transformed Allometric Equations. Ecology 107 64:209-210.

108 Su, Y.-S., and Masanao Yajima. 2015. R2jags: Using R to Run "JAGS."

109 Sustainable Fisheries Act of the Magnuson-Stevens Fishery Conservation and Management Act. 110 1996. Silver Spring: U.S. Department of Commerce, National Oceanic and Atmospheric 111 Administration, National Marine Fisheries Service.

112 Venables, W. N., and B. D. Ripley. 2002. Modern Applied Statistics with S4th edition. Springer, 113 New York. 
Appendices: Broadening Age Structure

115 TABLE A.1 Multinomial coefficients used to estimate length-at-age for Tautog in the Long

116 Island Sound stock assessment. Length-at-age was estimated independently for each of the four

117 selectivity blocks (period of relatively consistent regulations) using fish sampled in both fishery-

118 dependent and independent surveys (Table 1).

\begin{tabular}{llllllll}
\hline $\begin{array}{l}\text { Selectivity } \\
\text { Block }\end{array}$ & $\begin{array}{l}\text { Age } \\
\text { (years) }\end{array}$ & Intercept & Slope & $\begin{array}{l}\text { Selectivity } \\
\text { Block }\end{array}$ & $\begin{array}{l}\text { Age } \\
\text { (years) }\end{array}$ & Intercept & Slope \\
\hline 1 & 2 & -162.669 & 10.230 & 3 & 2 & -3.089 & 0.281 \\
1 & 3 & -173.181 & 10.742 & 3 & 3 & -9.847 & 0.613 \\
1 & 4 & -182.976 & 11.133 & 3 & 4 & -15.645 & 0.830 \\
1 & 5 & -194.465 & 11.508 & 3 & 5 & -21.871 & 1.027 \\
1 & 6 & -206.062 & 11.840 & 3 & 6 & -28.572 & 1.209 \\
1 & 7 & -217.696 & 12.136 & 3 & 7 & -35.250 & 1.373 \\
1 & 8 & -226.105 & 12.329 & 3 & 8 & -42.197 & 1.532 \\
1 & 9 & -233.617 & 12.495 & 3 & 9 & -46.471 & 1.618 \\
1 & 10 & -241.921 & 12.668 & 3 & 10 & -53.729 & 1.764 \\
1 & 11 & -247.378 & 12.771 & 3 & 11 & -56.494 & 1.811 \\
1 & 12 & -252.481 & 12.866 & 3 & 12 & -62.957 & 1.931 \\
1 & 13 & -255.774 & 12.919 & 3 & 13 & -66.842 & 2.002 \\
1 & 14 & -265.918 & 13.109 & 3 & 14 & -68.362 & 2.022 \\
1 & 15 & -265.930 & 13.093 & 3 & 15 & -71.806 & 2.081 \\
1 & 16 & -269.592 & 13.187 & 3 & 16 & -79.435 & 2.229 \\
2 & 2 & -2.874 & 0.273 & 4 & 2 & -2.587 & 0.250 \\
2 & 3 & -14.189 & 0.845 & 4 & 3 & -12.137 & 0.729 \\
2 & 4 & -20.509 & 1.101 & 4 & 4 & -20.847 & 1.054 \\
2 & 5 & -27.991 & 1.348 & 4 & 5 & -31.684 & 1.399 \\
2 & 6 & -33.946 & 1.518 & 4 & 6 & -36.226 & 1.523 \\
2 & 7 & -39.864 & 1.667 & 4 & 7 & -46.729 & 1.775 \\
2 & 8 & -45.775 & 1.807 & 4 & 8 & -55.479 & 1.966 \\
2 & 9 & -50.922 & 1.914 & 4 & 9 & -62.063 & 2.099 \\
2 & 10 & -57.317 & 2.045 & 4 & 10 & -73.189 & 2.316 \\
2 & 11 & -64.076 & 2.176 & 4 & 11 & -83.274 & 2.503 \\
2 & 12 & -66.309 & 2.216 & 4 & 12 & -90.806 & 2.632 \\
2 & 13 & -67.336 & 2.231 & 4 & 13 & -83.826 & 2.497 \\
2 & 14 & -72.748 & 2.332 & 4 & 14 & -91.547 & 2.644 \\
2 & 15 & -74.334 & 2.359 & 4 & 15 & -89.283 & 2.587 \\
2 & 16 & -81.890 & 2.509 & 4 & 16 & -350.977 & 7.132 \\
\hline & & & & & & &
\end{tabular}

119 
Appendices: Broadening Age Structure

120 TABLE A.2. Life history parameters, description, and value calculated for the Long Island

121 Sound Tautog stock assessment. Weight-length relationships were estimated independently for

122 each selectivity block (period of relatively consistent regulations) as preliminary analysis

123 indicated changes in this relationship during the assessment period.

\begin{tabular}{llll}
\hline Parameter & \multicolumn{1}{c}{ Description } & \multicolumn{1}{c}{ Selectivity Block } & \multicolumn{1}{c}{ Value } \\
\hline \multicolumn{4}{c}{ Von Bertalanffy growth parameters } \\
$L_{\infty}$ & Asymptotic length (cm) & 58.7 \\
$K$ & Growth coefficient & 0.171 \\
$t_{0}$ & Time at zero length (year) & -0.08 \\
& & Weight-length relationship & \\
$\alpha_{1}$ & Length-weight coefficient & 1 & $1.80 \mathrm{E}-05$ \\
$\beta_{1}$ & Length-weight exponent (cm to kg) & 1 & 3.07 \\
$\varepsilon_{1}$ & Bias correction factor & 1 & 1.007 \\
$\alpha_{2}$ & Length-weight coefficient & 2 & $1.40 \mathrm{E}-05$ \\
$\beta_{2}$ & Length-weight exponent (cm to kg) & 2 & 3.13 \\
$\varepsilon_{2}$ & Bias correction factor & 2 & 1.009 \\
$\alpha_{3}$ & Length-weight coefficient & 3 & $2.00 \mathrm{E}-05$ \\
$\beta_{3}$ & Length-weight exponent (cm to kg) & 3 & 3.02 \\
$\varepsilon_{3}$ & Bias correction factor & 3 & 1.011 \\
$\alpha_{4}$ & Length-weight coefficient & 4 & $2.10 \mathrm{E}-05$ \\
$\beta_{4}$ & Length-weight exponent (cm to kg) & 4 & 2.99 \\
$\varepsilon_{4}$ & Bias correction factor & 4 & 1.016 \\
\hline
\end{tabular}

124

125 
Appendices: Broadening Age Structure

126 TABLE A.3 Length-specific noncompliance rates for fish smaller than the current minimum size

127 limit for Tautog harvested in Long Island Sound from 2012-2015. These rates were applied in

128 stanza 1 of the harvest slot limit removal estimates.

\begin{tabular}{ll}
\hline Length $(\mathrm{cm})$ & Noncompliance rate \\
\hline 27 & 0.0000130 \\
28 & 0.0000473 \\
29 & 0.0001557 \\
30 & 0.0004905 \\
31 & 0.0010862 \\
32 & 0.0026338 \\
33 & 0.0058760 \\
34 & 0.0129561 \\
35 & 0.0250747 \\
36 & 0.0454834 \\
37 & 0.0806935 \\
38 & 0.1340782 \\
39 & 0.2041256 \\
\hline
\end{tabular}

129

130 TABLE A.4. Comparison of biological reference points estimated in the 2016 ASMFC Tautog

131 Long Island Sound stock assessment and the assessment developed for the current study.

\begin{tabular}{lll}
\hline Reference point & ASMFC assessment & Current study assessment \\
\hline $\mathrm{SSB}_{\text {Terminal }}$ & $1,603 \mathrm{mt}$ & $1,937 \mathrm{mt}$ \\
$\mathrm{SSB}_{\text {Target }}$ & $2,980 \mathrm{mt}$ & $3,397 \mathrm{mt}$ \\
$\mathrm{SSB}_{\text {Threshold }}$ & $2,238 \mathrm{mt}$ & $2,549 \mathrm{mt}$ \\
$\mathrm{F}_{\text {Terminal }}$ & 0.51 & 0.75 \\
$\mathrm{~F}_{\text {target }}$ & 0.28 & 0.29 \\
$\mathrm{~F}_{\text {Threshold }}$ & 0.49 & 0.54 \\
\hline
\end{tabular}

132 


\section{DATA}

Independent Surveys Dependent Surveys Biological Studies (State) (State/Federal/ALS)

- Abundance indices

- Life history

- Length

- Age

- Weight

- Sex
- Effort index

- Catch

- N-at-age

- Age

- Weight
- Discard mortality

- Natural mortality

- Maturity-at-age

- Proportion of year prior to spawning

\section{Sex}

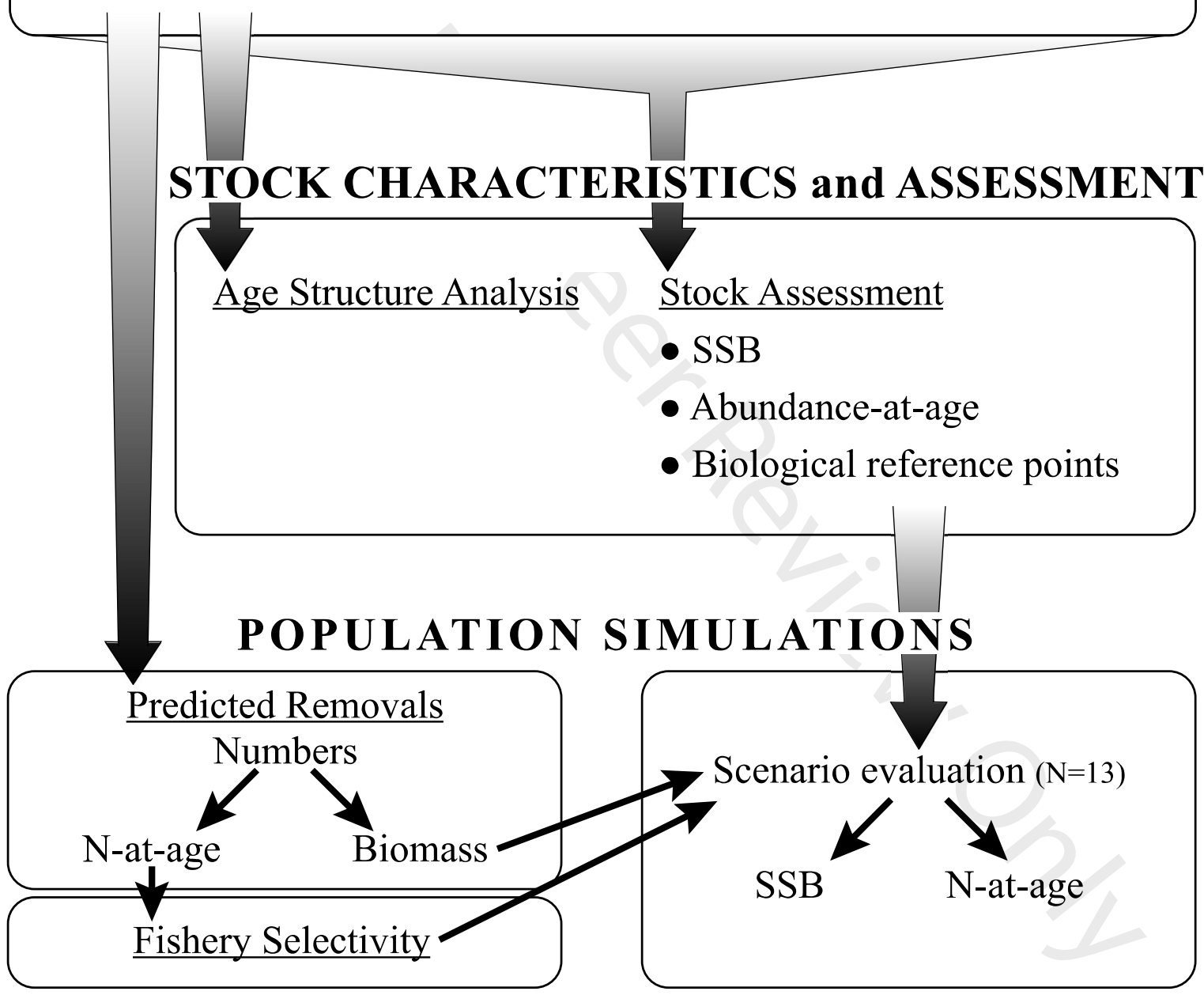

FIGURE 1. Schematic representation of the data flow and modeling. Data are collected by state and federal agencies and the American Littoral Society (ALS) include stratified random fishery-independent surveys, fishery-dependent angler surveys of catch and harvest, and biological studies. Independent survey data was used to analyze age structure. All available surveys and biological data were used in the statistical catch-at-age stock assessment model. Dependent surveys informed the removal (sum of harvest and dead discards) for the harvest slot limits and both dependent and independent surveys informed fishery selectivity for the harvest slot limits. Fishery selectivity and the assessment model parameterized the forward population simulations for each of the 13 scenarios evaluated. Spawning stock biomass (SSB) and numbers-at-age ( $\mathrm{N}$-at-age) were estimated in the population simulation model. 


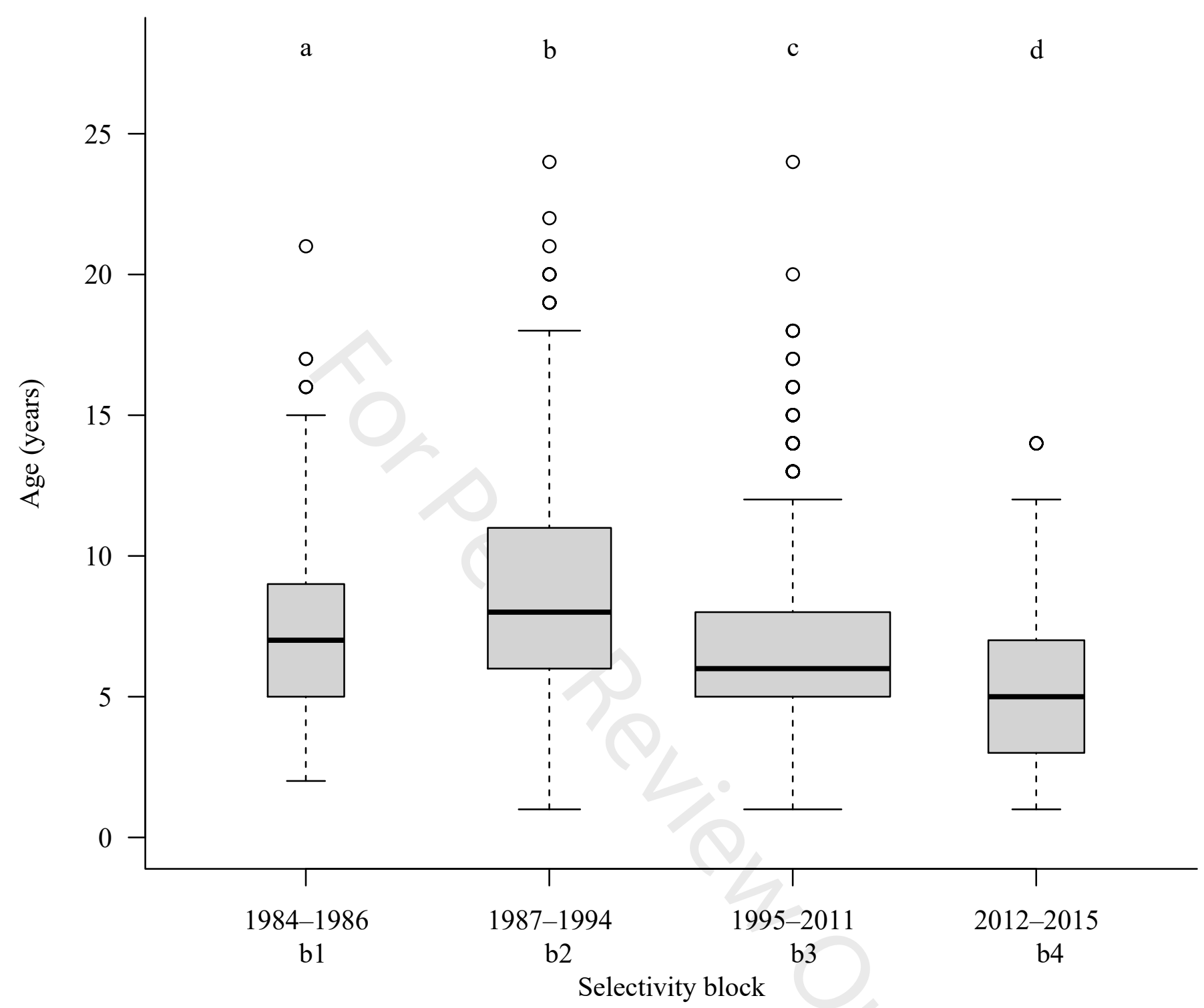

FIGURE 2. Change in age structure of female Tautog caught in the Connecticut Long Island Sound Trawl Survey by fishery selectivity block (b). The size distribution of females is shown (in each box the center line represents the median, the lower and upper boundaries represent the 25 th and 75 th percentiles, whiskers extend to 1.5 times the interquartile range, single point outliers (which also indicates maximum age observed in each selectivity block) are indicated with circles, and box width varies with sample size. The survey targeted 200 stations per annum in the spring and fall (the average annual number of station per selectivity varied: $b 1=218, b 2$ $=243, \mathrm{~b} 3=182, \mathrm{~b} 4=200)$. The mean age in each selectivity block was significantly different from each other (all p-values $<0.0001$ ) as analyzed by Tukey's honest significant difference (indicated by the letters above the boxes). 


\section{Small-narrow}
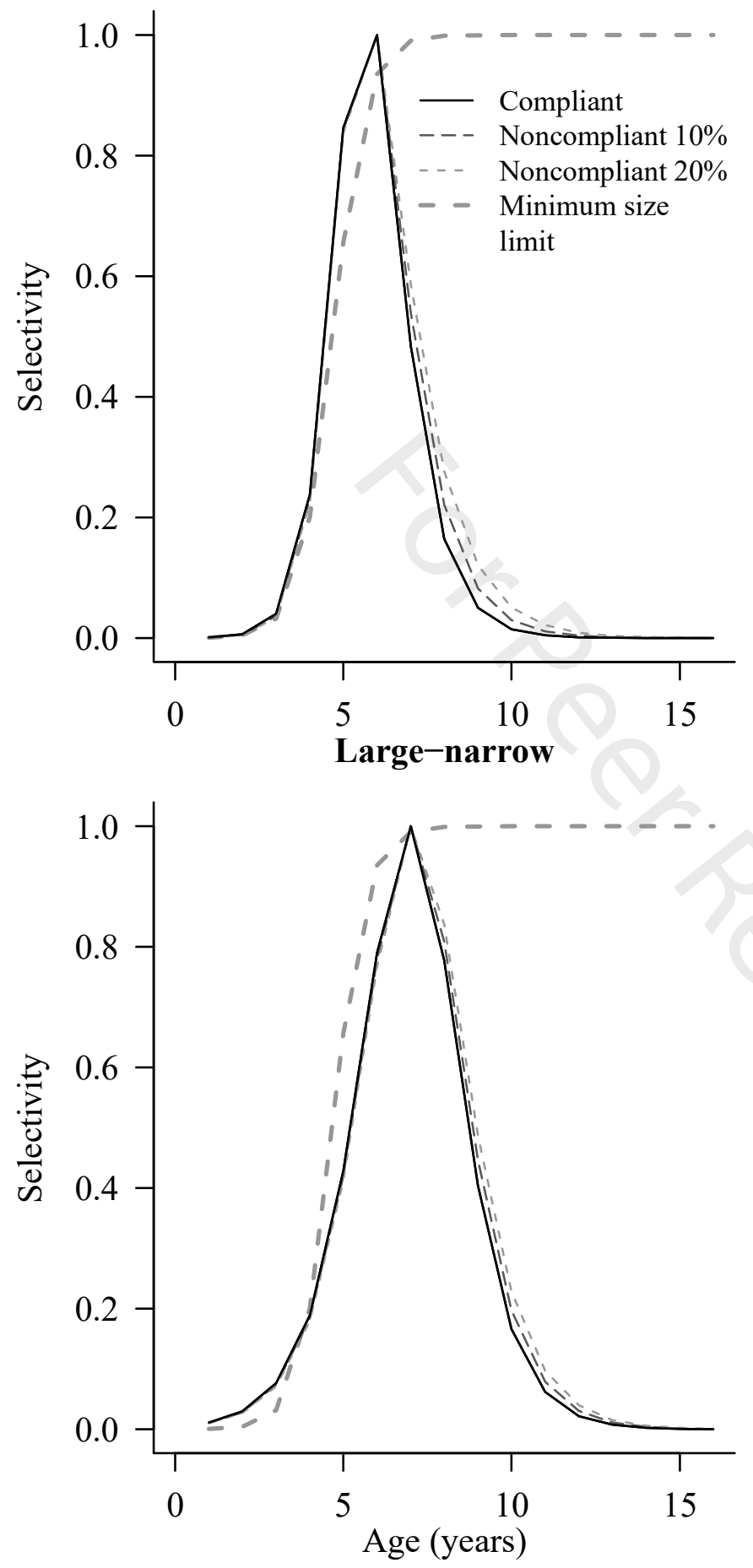

Small-wide
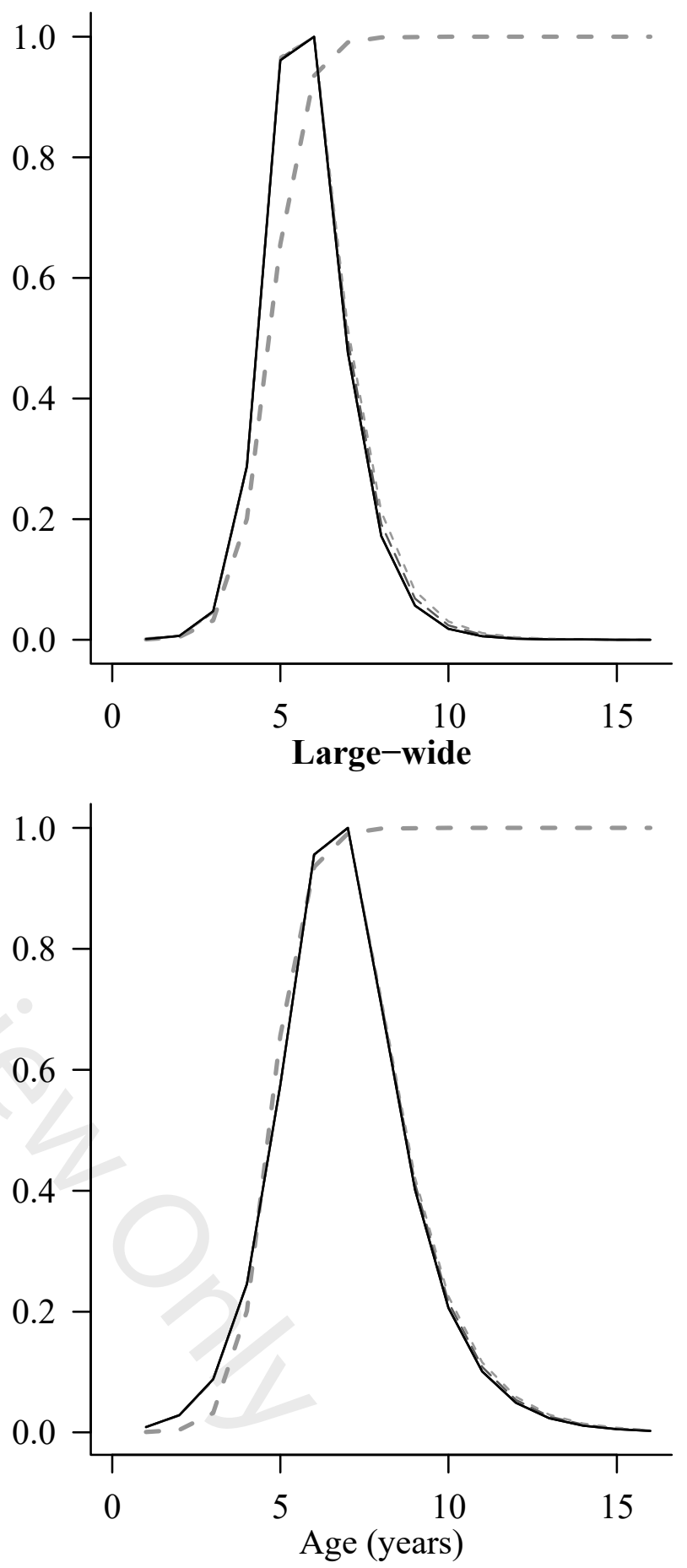

FIGURE 3. Selectivity-at-age used in population projections. Full compliance and noncompliance with the upper size of the harvest slot limit were evaluated at $10 \%$ and $20 \%$. Selectivity-at-age with the current minimum size limit (MSL) of 16" is included in each panel. 

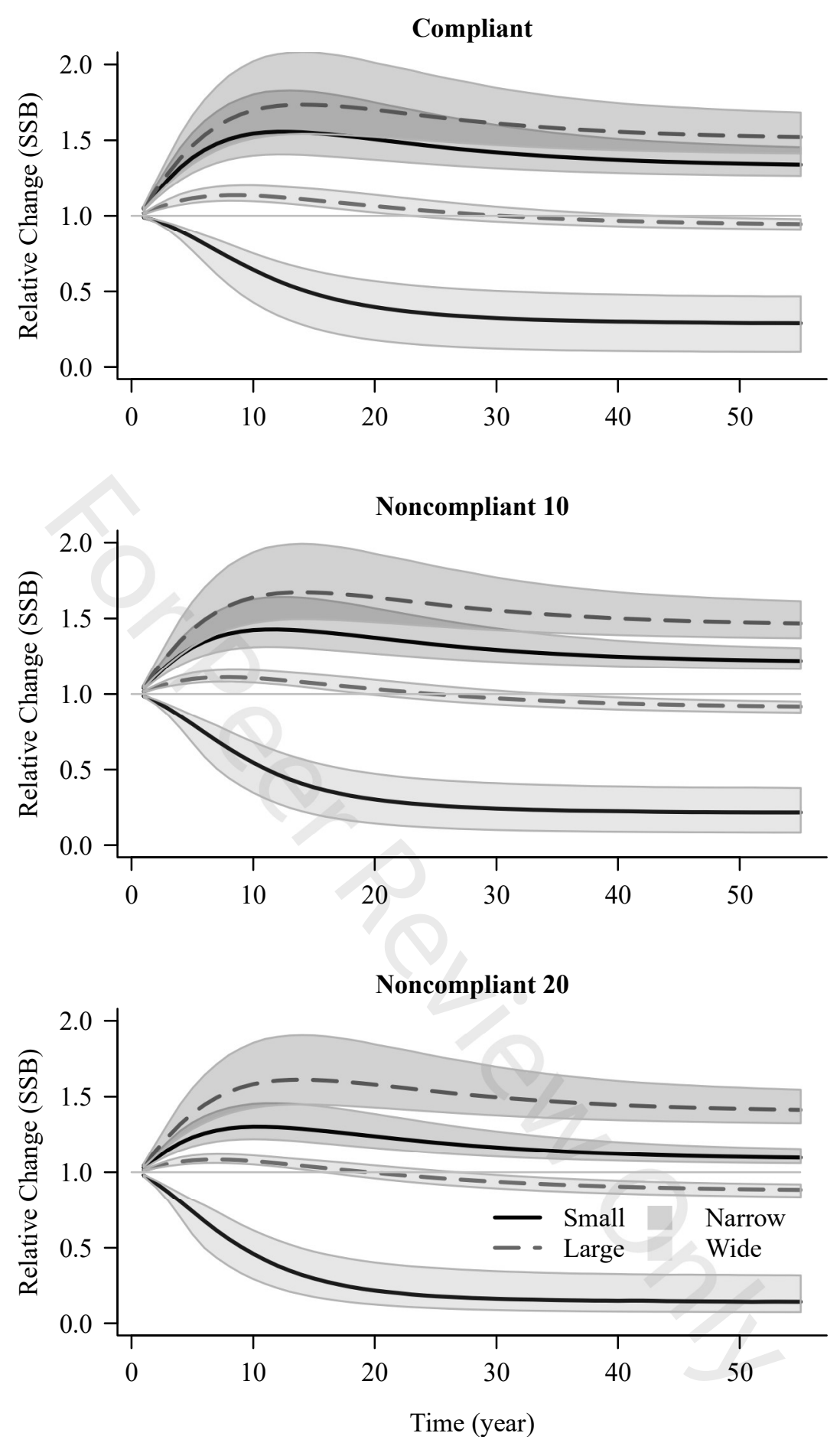

FIGURE 4. Median change in SSB when managed with harvest slots limits, relative to management with minimum size limits. Full compliance (top panel), and noncompliance with upper slot limit were evaluated at 10\% (middle panel), and 20\% (bottom panel). Shaded regions indicate $90 \%$ confidence limits of the forward population simulations. Darker colors that do not appear in the legend indicate overlap. 

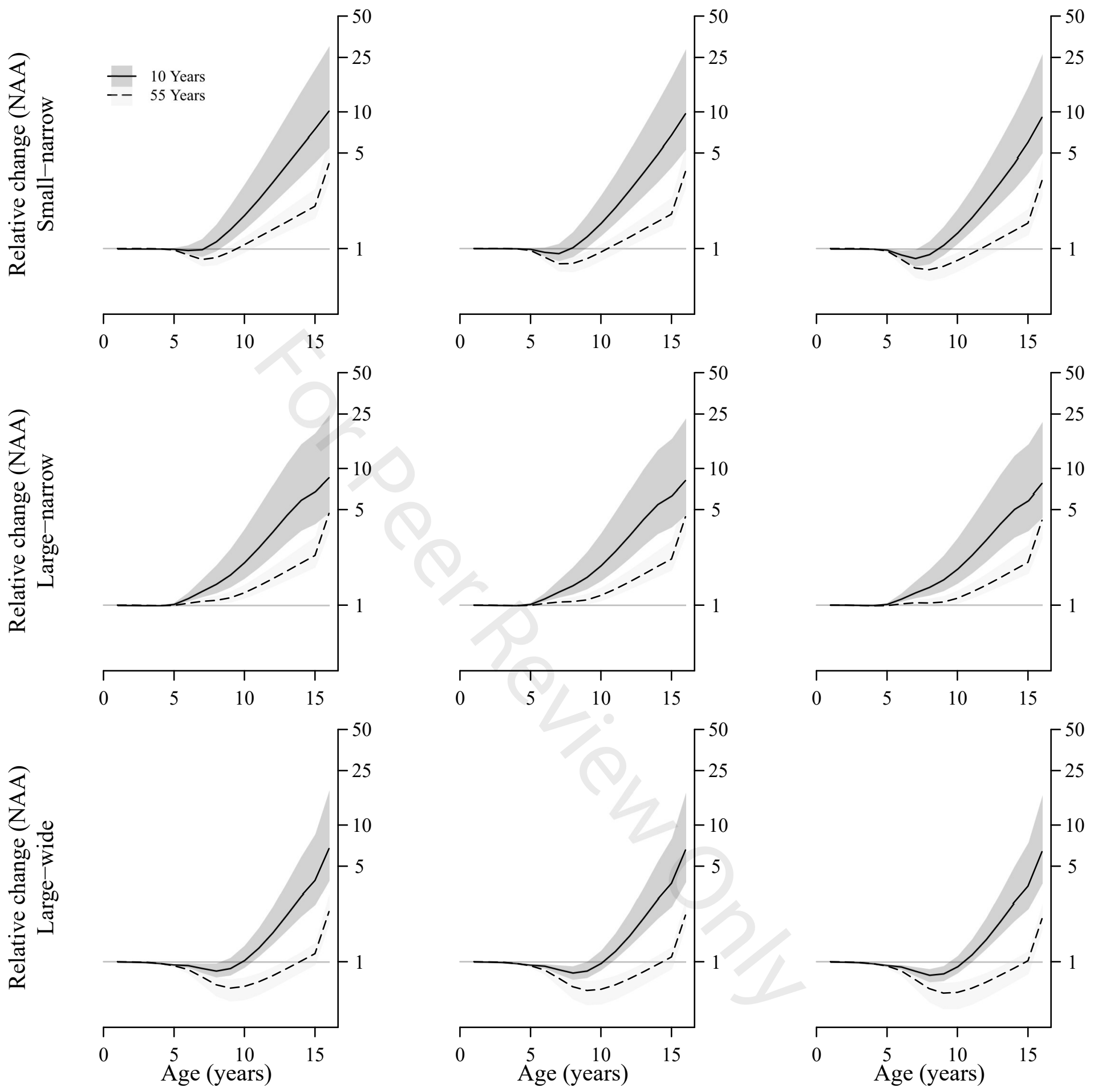

FIGURE 5. Median change in abundance-at-age, for three harvest slot limit scenarios relative to management with minimum size limits (MSL). Changes in abundance-at-age after 10 and 55 years of management for the fully compliant models and $10 \%$ and $20 \%$ noncompliance with the upper slot limit are shown. Shaded regions indicate $90 \%$ confidence limits estimated from forward population simulations. Darker colors that do not appear in the legend indicate overlap. Changes in abundance-at-age are not shown for the small-wide slot, where SSB crashed. 


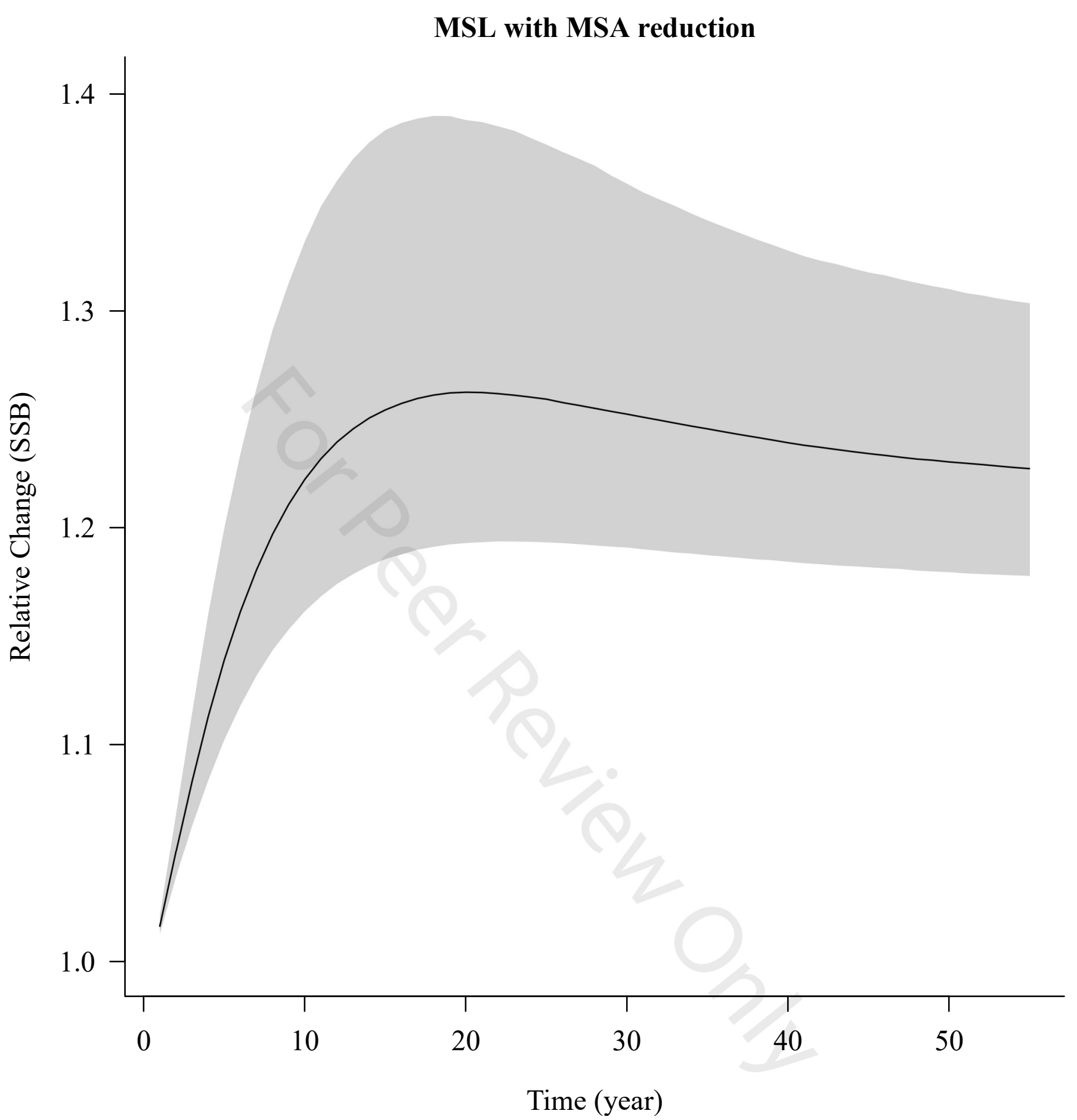

FIGURE A1. Median changes in spawning stock biomass (SSB) when managed with the minimum size limit and the harvest reduction in compliance with the Sustainable Fisheries Act of the Magnuson-Stevens Fishery Conservation and Management Act, relative to the current Atlantic States Marine Fisheries Management Commission strategy. Shaded regions indicate 90\% confidence limits estimated from forward population simulations. 


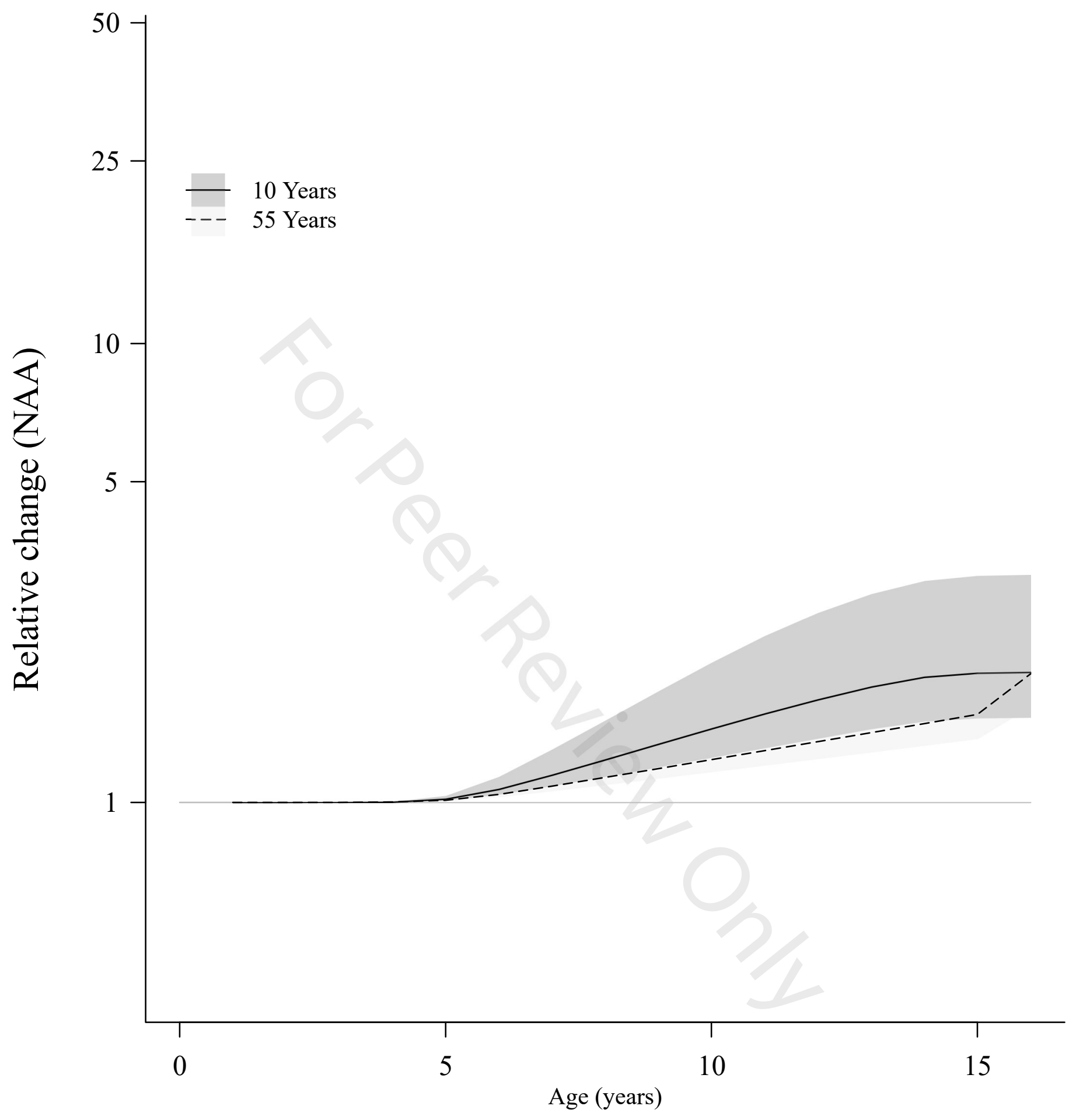

FIGURE A2. Median change in abundance-at-age (NAA), when managed with the minimum size limit and the harvest reduction in compliance with the Sustainable Fisheries Act of the Magnuson-Stevens Fishery Conservation and Management Act, relative to the current Atlantic States Marine Fisheries Management Commission strategy. Changes in abundance-at-age after 10 and 55 years of management is shown. Shaded regions indicate $90 \%$ confidence limits estimated from forward population simulations. 